\title{
Religiosidad y comunicación interespacial en la Edad Media. Los viajes celestiales en el Poema de Santa Oria
}

\author{
ANTONIO CEA GUTIÉRREZ \\ Dpto. de Antropología de España y América \\ CSIC. Madrid
}

Las hagiografías como modelos de vida de la época, en este caso el de la emparedada Oria, tan envidiados como imposibles, y dentro del estilo que define esta tipología: extremada santidad, intensa relación con lo divino, espectacularidad y abundancia de milagros que compiten en rareza con el grado de virtud de sus personajes, encierran como problema inherente, aun para quienes se proponían imitar estos exempla, presentados en su tiempo como sucedidos, la credibilidad del narrador y de sus fuentes, escollos que, desde el inicio del Poema, Gonzalo de Berceo, el gran poeta del siglo XIII intenta despejar.

Santa Oria, nacida en Villavelayo en el año 1043, fue hija de García y Amuña y vivió emparedada nueve años como lega y dieciocho de monja en el monasterio riojano de Suso, donde murió el 12 de marzo de 1070. Su biografía, escrita por el clérigo Muño, 1045-1078, hoy perdida, fue retomada por Berceo c. 1252 como Poema de Santa Oria, probablemente su última obra. Se estructura en siete apartados: Prólogo e introducción, 1. ${ }^{a}$ visión, 2. ${ }^{a}$ visión, 3. ${ }^{a}$ visión, muerte de Oria y epílogo. El núcleo de esta vita lo constituyen las visiones del cielo, como premio a su vida de mortificación y emparedamiento. En ellas accede a las distintas jerarquías de santos, habla con Voxmea, la guardiana de su vida, oye la voz de Dios, es visitada en su "ciella" o celda por Santa María, y tiene ocasión de relacionarse con ángeles y especialmente con las vírgenes, Eulalia, Águeda y Cecilia, que la tratan como compañera y le sirven de guías en estos viajes.

Planteamos en este trabajo las relaciones que se establecen entre divinidades y humanos y las salidas ocasionales de sus respectivos espacios (cielos, paraíso, purgatorio, tierra) por don, virtud o gracia. Despla- 
zamientos del cielo a la tierra para ayudar a lograr la consecución de ese lugar deseado, unas veces de manera temporal (a través de los viajes visionarios), otras para heredarlo (muerte santa).

Se establecen entre los dos mundos unos grados de parentesco, vínculos y relaciones positivas (acumulación de méritos de una parte y de finezas y premios de la otra). Esta coloratura parental de amistad o en relación de maestro-discípulo, en el caso de Santa Oria va desde el tratamiento de amo/siervo fiel al de padre-madre (Dios y Santa María) - bija. También se da el vínculo de hermana y comadre (entre Oria y las tres vírgenes: Eulalia, Cecilia y Águeda, que la guían en las salidas celestiales y la pasean entre las diferentes jerarquías de santos).

Aparecen, además, las figuras de ayudantes y arrieros celestiales: los ángeles mancebos que con sus bordones preparan un carro para una de las ascensiones de Oria; perfil que incluiría también a las otras tres vírgenes no identificadas que -en rango de ancilas - bajan a hermosear la celda de la emparedada para la visita de Santa María, que se convierte en improvisada estancia de aparato.

La figura de Voxmea en el cielo, al final del haz y jerarquía de vírgenes guardándole la sellada silla a Oria, así como las de su maestra, Urra$\mathrm{ca}$, y la condiscípula Justina (ambas ya en el cielo), forman un grupo de relación doctrinal de maestras-discípulas, además de que el personaje de Voxmea simbolice el alter ego, super yo, y destino glorioso de nuestra santa serrana. El mismo sentido, nos parece, tienen la paloma de Oria y las de las tres vírgenes guionas (con papeles e identidad no claramente - definidos), como representaciones del alma y de la gracia, que es motor para el cielo.

Aunque, por su interés, desarrollamos en artículo aparte el tema de los premios celestiales en el Poema de Santa Oria, especialmente el de la silla, sí esbozamos la fijación de Oria por el trono-galardón y lo que para ella significa: en la tierra, estatus, poder, realeza, dominio, carencia de fatigas, ausencia de trabajos y lo mismo en el cielo, cuya hechura se conforma como una corte a la medida terrenal. Oria desea convertir, en sus bodas con "Don Cristo", esa silla en tálamo; idea que produce los vínculos más fuertes en los grados de: amado-amada, novios, esposo-esposa, alma-Cristo.

El espacio celestial que describe Berceo en el Poema es un cielo fragmentado y parcial donde están establecidas las seis jerarquías de Santos, cuya ocupación es exclusivamente áulico-litúrgica: cantar y hacer procesiones para el rey celestial. Este primer ámbito, que parece calcado de una catedral, equivaldría al coro bajo hispano, abierto por su puerta exterior a las visiones de Oria y cuyas claves no guarda San Pedro sino 
una monja que le suple en el oficio. La otra puerta de ese coro que da acceso al Sancta Sanctorum permanece cerrada y la comunicación entre ambos espacios - coro y santuario, santos y divinidad- se establece solo a través de la voz e intercambios, ciegos, de parlamentos (al menos así lo percibe Oria). Hay un velo que oculta la presencia de la divinidad: Trinidad-María, y también la de su corte angélica. El cielo en el Poema muestra una primera parte donde no se llega aún al protocolo de la coronación del alma, que desarrolla Berceo en Los signos del Juicio Final. Es un cielo a la manera monástica y espacio eclesiástico.

Pero hay otro cielo temporal, inferior, presentado como descanso en la jornada que es paradisíaco, situado en el Monte Oliveti, de sensaciones exclusivamente terrenales: olores, frutos, sabores, temperaturas, colores, con probables adherencias de pensamiento islámico e hispano, visión que aparece también en Los Milagros de Nuestra Señora.

Las visiones celestiales en el Poema de Santa Oria se suceden como una serie de experiencias secuenciadas — subidas y bajadas alternando en arsis y tesis - a manera de melodía gregoriana, lo que en la decoración románica se denomina "dientes de perro", o "de sierra": $1^{\text {a }}$ visión o arrebato a los cielos $\pi ; 2^{\mathrm{a}}$ visión: descensión de María $\boldsymbol{\chi}_{;} 3^{\mathrm{a}}$ visión o subida al Monte Oliveti $\boldsymbol{\gamma}_{\text {; }} 4^{\mathrm{a}}$ visión: bajada de los santos a por el alma de Oria $\searrow$; 5 , ensoñación de Amuña y ubicación de Oria a las puertas del cielo $\rtimes$.

Se da un trasiego de subidas y bajadas, una intercomunicación entre el cielo y la tierra, con espacios intermedios: la scala caeli, el Monte Oliveti, la noche purgatorial de Oria en espera, a las puertas de la gloria.

¿Cómo son esos viajes? Generalmente se califican como VISIONES y apariciones, percibidas con los ojos interiores del alma, en el lecho, durmiendo, y su final se manifiesta con la apertura de los ojos corporales para significar la vuelta al mundo cotidiano y al estado de vigilia. Solo la madre, Amuña, define su experiencia visionaria como ENSOÑACIÓN. Cuando en el verso $111 \mathrm{~cd}$ se dice: "en muy poquiello tiempo, al cuerpo la tornaron" ise están solamente contraponiendo términos como "sueño"/ "Vigilia", "dormir"/secordar-despertar", o se habla abiertamente de éxtasis en sentido estricto y salida temporal del alma?

Se barajan en la obra conceptos como: verdad, realidad, milagro, visión; éxtasis, ensoñación, traslados, imaginaciones; posibilidades todas que en esa época se admiten en los casos de personas de vida santa - sin los riesgos ni recelos que esas experiencias y sus manifestaciones escritas conllevaron en épocas posteriores a los ojos de la Iglesia-, proponiéndolas como exempla.

Nos preguntamos hasta dónde llega la originalidad en el texto de Berceo sobre la visión del cielo de su tiempo y las diferencias con las 
fuentes de Muño, que aportaría a su vez la del suyo, con probables adherencias anteriores. ¿Cuál es la matriz cultural, doctrinal e iconográfica en que se fundamenta? La Jerusalén celestial y el Paraíso se presentan como una construcción edilicia. En los siglos XII y XIII el Paraíso comienza a interpretarse no como locus sino como status o categoría de recompensa divina. Su localización sigue en el Poema las narraciones escatológicas musulmanas que lo sitúan en el Monte Oliveti de Jerusalén, oponiéndose a la visión occidental cluniacense que aparece en el Liber Sancti Iacobi, ubicándolo en Roma, afianzando así la lógica universalista. Richard Beeker ${ }^{1}$ sostiene que Berceo ¿o Muño? bebe en fuentes locales para el Poema y la Vida de Santo Domingo de Silos, mientras que utiliza para los Milagros... una colección de miracula del siglo XII, que debió de estar entonces muy extendida en Europa.

Como Ariel Guiance ${ }^{2}$ señala, se dan tres posiciones acerca de la visión del cielo en la Edad Media: a) Cielo-vergel no urbano, concepto que divulgan monjes y frailes, retomado luego en el Renacimiento. b) El redescubrimiento de la ciudad lleva a la idea de un cielo como Nueva Jerusalén cuyos modelos en la tierra son la catedral gótica y el castillo. c) Para los pensadores de élite, teólogos, etc., el cielo se entendía como el conocimiento intelectual de Dios, y las especulaciones de los frailes (del apartado a), solo como diversión para el pueblo.

1 Richard BEEKER, Gonzalo de Berceo's Milagros und ibre Gundlagen (Estrasburgo, 1920)

2 Ariel GUIANCE, Los discursos sobre la muerte en la Castilla Medieval (ss. VII-Xv) (Valladolid: Junta de Castilla y León, 1998), especialmente el capítulo "La muerte del santo". Ver, además: J. A. Ruiz Domínguez, "Pecadoras y santas en el mundo de Gonzalo de Berceo", La religiosidad de las mujeres en la Edad Media bispana (Madrid: Laya, 1989), pp. 47-58. Daniel Devoto, Gonzalo de Berceo et la musique. Études sur deux mots espagnols anciens (Paris: La Sorbonne, 1955). José FrADEJAS LEBRERO, "La forma litánica hasta Berceo", Actas de las III Jornadas de Estudios Berceanos (Logroño: Instituto de Estudios Riojanos, 1981), pp. 63-71. W. R. Cook y R. B. Herzmann, La visión medieval del mundo (Barcelona: Vicens Vives, 1985). R. RAPP, La Iglesia y la vida religiosa en Occidente a fines de la Edad Media (Barcelona: Labor, 1973). A. VAuCHEZ, La Espiritualidad del Occidente Medieval (Madrid: Cátedra, 1985). R. PERNOUD, Les saints au Moyen Âge (Paris: Plon, 1984). E. MITRE FERNÁNDEZ, La muerte vencida. Imágenes e bistoria en el Occidente medieval (1200-1348) (Madrid: Encuentro, 1988). H. R. PATCH, El otro mundo en la literatura medieval (México: F.C.E., 1956). J. VILLÁN, "Berceo, una religión apacible y liberadora", Historia 16, II (1977). J. A. RuIZ DOMínGUEZ, La historia de la Salvación en la obra de Gonzalo de Berceo (Logroño: Instituto de Estudios Riojanos, 1990). B. DutTon, "Berceo's bad bishop in the Vida de Santa Oria", Medieval Studies in honor of Robert White Linker (Madrid: Castalia, 1973), pp. 95-102. F. BAÑos VAlLEjo, La hagiografía como género literario en la Edad Media (Oviedo: Univ. de Oviedo, 1989). 


\section{Prólogo E INTRODUCCIÓN DE BERCEO}

(Coplas 1-27) El clérigo emilianense en un tono intimista y biográfico considera esta Vita y exemplum como obra de madurez y colofón a su profesión pasionaria. En deuda, quizá de paisanaje, y apremiado por la fatiga de la edad, no quiere morir sin romancear la vida de Oria, la doncella emparedada (copla 2). Aborda ya en la copla 4 la idea de la predestinación, asociada al nombre propio de la santa, que heredará una silla celestial más preciosa que las piedras y el oro. Por razones de espacio, nos vemos obligados a tratar en capítulo aparte el tema de los galardones celestiales, la silla, la corona y la palma, en la obra de Berceo, especialmente en el Poema. Oria (5bd) ha sido elegida para experimentar una gran visión en los cielos.

Se plantea luego (copla 6abd) la importancia de la transmisión oral y escrita: "nos versificamos, nos contamos, nos escripto lo fallamos", poniendo a Dios por testigo de su veracidad. Sostiene Berceo que no hay ápice de falsedad o fantasía en el Poema, argumentando la autoridad de su fuente, Muño, de quien toma el dictado, con el siguiente silogismo: veracidad $\rightarrow$ bondad $\rightarrow$ santidad $\leftrightarrow$ sabiduria.

Muño (7-8 y 9), "omne bien letrado", había realizado una historia de vida teniendo a la propia Oria y a su madre Amuña como informantes. Él jugaba con la ventaja de la ascendencia por su magisterio espiritual, ellas se sentían, quizá, obligadas por santa obediencia a contar en sus visitas o confesiones algo que en otras circunstancias hubieran sellado con el silencio ${ }^{3}$.

El consuetudinario incipit o invocatio con el que nuestro autor se dispone a comenzar el relato es la fórmula usual de cortesía, el Domine ad adjuvandum me festina / "Dios nos dé la su gracia" (9c), que todo cristiano empleaba para iniciar, proseguir y llevar a término cualquier acción comunitaria, aquí un escrito calificado como "estorian: "Sigamos la estoria" (10b) ${ }^{4}$.

3 Es el caso de Teresa de Ávila, mujer ya de letras, obligada por sus superiores a poner por escrito su vida y experiencias místicas: "Quisiera yo que, como me han mandado y dado larga licencia para que escriba [...] suplico [a Dios] me dé gracia para que con toda claridad y verdad yo haga esta relación que mis confesores me mandan". Siguiendo esta santa con el orden de argumentos y método utilizados ya en este género biográfico por Berceo, continúa: “El tener padres virtuosos y temerosos de Dios me bastara, si yo no fuera tan ruin"... (Libro de la Vida, Prólogo y Cap. I. Cito por la 4." edic. de la BAC, Madrid, 1974, p. 28).

4 Esta costumbre de comenzar cualquier obra en nombre de Dios o de María, se ha mantenido también en danzas y bailes rituales, como el que celebraba los domingos por la tarde la mocedad en la bolera de Parres (Llanes), acompañado de tambor y pandero que se iniciaba cantando el estribillo siguiente: 
Viene, en segundo lugar, la filiación intachable (17ab y 18a): "Sanctos fueron sin dubda e justos los parientes, que fueron de tal fija engendrar merecientes". Se hace patente aquí la idea del ennoblecimiento de la estirpe también por la santidad, gracia que, en parte, parece heredarse, y de nuevo se reitera en el verso siguiente: "Apriso las costumbres de los buenos parientesn; la nobleza de la sangre es reemplazada por la nueva nobleza espiritual.

En tercer lugar, aparece en el texto la fama de santidad del personaje que presenta como exemplum, no reducida a la admiración local —los pueblos de su tierra", sino que traspasaba con mucho sus fronteras: "salié a luengas tierras" (22cd). En esta historia de santidad, Oria aparece perfilada desde el principio con tres atributos como de letanía (25abd): Era "vaso de caridat, templo de paciencia e de humildat" y "luz e confuerto de la su vezindat", que es lo que se pide de todo modelo de perfección; virtudes en grado heroico y ejemplo o espejo en quien sus devotos -en este caso aún solo comarcanos- se miran. La inclinación que en expresión de Berceo "foradaba los cielos" (26d) parece anticipo premonitorio de sus viajes.

LA PRIMERA VISIÓN: PRESANTIFICACIÓN Y ENCUENTRO CON LAS TRES VÍRGENES GUIONAS

(Coplas 28-29) El cómo y el cuándo de esta primera visión tuvo lugar la noche del 27 de diciembre, festividad de Santa Eugenia: "vido de visiones una infinidad" (c), gracia que Berceo justifica como síntoma de santidad (d) 5 . Sucedió, acabados los maitines, en un sueño reparador, que "vido

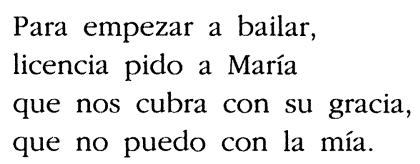

(Recogido de mi abuela, Isabel Amieva Cué (de 83 años, +en 1968). De igual manera solía comenzar el canto del ramo por las mozas, con la petición de licencia; como éste para la fiesta de San Blas, que recogimos en Santibáñez de la Sierra (Salamanca):

le pideremos [sic] licencia

a la Reina de los Cielos.

5 Como acertadamente señala Ariel GuiAnCE en "Sobre el espacio y el tiempo de trasmundo en la literatura castellana medieval", Temas Medievales, 2 (Buenos Aires: CONICET, 1992), pp. 137-158, el término visión no tiene un sentido unívoco en la Castilla medieval. San Isidoro clasifica las visiones en: oculares, espirituales e intuitivas, y no privativas de los Santos. La Iglesia, por desconfianza de abusos, controló a partir del siglo XII las experiencias visionarias de gentes de no demostrada santidad. Guiance compara la transformación conceptual de las visiones en textos recogidos desde el 
en poca hora una grant visión" (29). Como acertadamente señala Isabel Uría $^{6}$, contrastan el poco tiempo real de duración y la intensa experiencia visionaria, sensación característica de esos sueños que, lógicamente, terminan al "recordar" o despertar: "Vido tres sanctas vírgenes de grant auctoridat, todas tres fueron mártires" $(30 \mathrm{ab})^{7}$. Se trata de Águeda, Eulalia y Cecilia, que destaca entre las otras por sus desposorios místicos con Cristo, tratando de suegra a la Gloriosa (31c). Sobresalen en estas vírgenes guionas el estatus y buena posición social dentro de la jerarquía celestial y se presentan ante Oria como vírgenes coronadas ${ }^{8}$ y con palomas blancas, no naturales, una en cada mano (33). La copla 34 describe el turbamiento que ocasiona la visión, casi como ingrediente iconográfico constante (fenómeno que no falta en la Embajada prototipo del Ángel a María, conocida también como la Salutación y, posteriormente, la Anun-

siglo VII al XIII, articulando sus elementos dentro de las coordenadas espacio/tiempo. Este tipo de relatos suele recogerse como "literatura de visiones" o "visionaria", "literatura de transmundo" o "literatura del más allá". Vid. Michel AuBRun, "Caractères et portée religieuse et sociale des Visions en Occident du $\mathrm{VI}^{\mathrm{e}}$ au $\mathrm{XI}^{\mathrm{e}}$ siècle", en Cabiers de Civilisation Médiévale, avril-juin (1980), pp. 109-130. Ver también Jacques LE GofF, "Aspects sauvantes et populaires des voyages dans l'au-delà au Moyen Age", L'imaginaire medieval (essais), (Paris: Gallimard, 1985), pp. 103-119. Carlos ALVAR, “El viatge al més enllà i la literatura artúrica", en AAVV, El món imaginari i el món maravellós a l'Edat Mitjana (Barcelona: Fundación Caixa des Pensions, 1986), esp. p. 81. Manuel DíAz y DíAz, Visiones del más allá en la Galicia durante la Alta Edad l/edia (Santiago de Compostela: Bibliófilos Gallegos, XXIV, 1985).

( Gonzalo de Berceo. Obra Completa. Ver la nota n. ${ }^{\circ} 29 .{ }^{2}$, p. 506, de la edición de Dutton (Madrid, Gobierno de la Rioja-Espasa Calpe, 1992).

7 En este caso y como atinadamente observa Vauchez en lo que denomina umodificación del campo semiótico de la santidad", a partir de los siglos XII-XIII, y con la afirmación del culto popular a los santos (al menos algunos destacados), los ángeles van siendo suplantados: La sainteté en Occident aux dernières siècles du Moyen Âge, d'aprés les procès de canonisation et les documents hagiographiques (Roma: École française de Rome, 1988), especialmente en el libro III, pp. 490 y ss. Añadiremos que, incluso las virtudes figuran como santos (el caso más paradigmático parece ser el de San Roque, personificación de la Caridad en tiempos de la Peste Negra). Valga como ejemplo iconográfico -que, por otra parte, guarda un cierto paralelo con el de nuestras tres vírgenes guionas- el conocido de las "Tres Virtudes", que Sassetta inmortaliza en el tema de los Desposorios Místicos de San Francisco con la Pobreza que, descalza en el vuelo, no deja de mirar desde lo alto al santo y presenta una rama de olivo igual que la $\mathrm{Hu}$ mildad; la Obediencia, en cambio, con el yugo sobre el hombro - como representando el ritual de arada- de los futuros desposados (Chantilly, Musée Condé).

8 "En el cielo coronada" es fórmula extendida al cantar, en poemas, historias, relaciones y gozos, los martirios de las vírgenes. En el alboral de Santa Águeda en Miranda del Castanar (Salamanca) se dice “... De Quinciano es abatida y en el cielo coronada". 
ciación, así como un parlamento que tranquiliza: en el pasaje evangélico, consolación por parte del arcángel y del Espíritu Santo y, como contrapartida de María, petición de identificación).

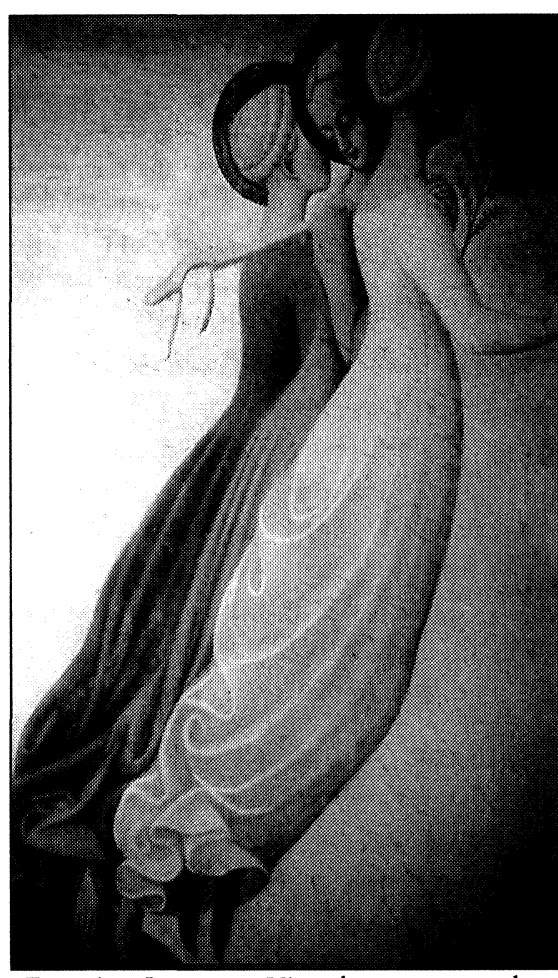

FIG. 1.-Las tres Virtudes presentadas como vírgenes voladoras y guionas. Sassetta, c. 1400-1450, detalle de los Desposorios Místicos de San Francisco (Chantilly, Musée Condé).

Sigue en el Poema de Santa Oria (35) un bello parlamento de sosiego de las tres vírgenes, que definen su viaje como aesta tan gran carreran (c). Se apean de su jerarquía y tratan a la santa serrana de "nuestra compañera" (d). Como en un drama clásico, las tres hablan a un tiempo. En la copla 46 se anuncia este viaje visual como un convite nupcial. En realidad, Berceo utiliza reiteradamente por boca de las vírgenes guionas, como parientas del novio (Cecilia es su esposa mística), las fórmulas de invitación a bodas y a vistas, fórmulas conservadas hasta hoy inalteradas en comarcas arcaizantes: "Convidarte venimos", "Envíanos [fulano, aquí Don Cristo]", "Que vengas"...

En su tiempo, quien leyera u oyera recitar estos versos, entendería sin esfuerzo esta intencionalidad. Se trata de una invitación literal y en toda regla a la prenupcial ceremonia de "vistas", "donas" o "dádivas graciosas por lí de matrimonio", no en vano llaman a Oria "novia" las guionas en el verso 67c. La santa serrana, en el verso 99c, verbalizará el deseo de convertir la silla celestial -que le presentarán como suya - en tálamo de sus nupcias con don Cristo: "querría seer novia" ". Dentro del protocolo y como respuesta de cor-

9 La ceremonia de las Vistas, conservada en La Alberca (Salamanca), que, entre las familias ricas podía prolongarse varias jornadas, tenía lugar a puerta cerrada y en fechas próximas a la boda. En ella se mostraban y cruzaban entre las dos familias los regalos, generalmente ropas, galas y algún mueble de aparato, a veces ya heredados; en las Vistas de Oria será la silla del cielo. La fórmula albercana de invitación al convite que pronuncia de puerta en puerta la hermana mayor del novio es: "fulano, venimos a convidarte, que vengas mañana a acompañar a los novios..." 
tesía a la copla 36 , contesta Oria en la 38 con cumplidos de indignidad: "allá serié complida toda la mi estorian. Tenía en este esposo, como se decía hasta hace poco tiempo, la mejor "proporción", y en el cielo, que aquí se utiliza como recurso retórico y final de sermones e historias, el premio de la silla.

La ceremonia o convite (39) tendrá lugar "Sobre los cielos", no en el locus amoenus, sino en el empíreo, y habrá de "Sobir" por algún tipo de escala. Sus inseguridades para dar eel sín quedan doblemente aquietadas: no estará entre desconocidos sino entre amigos y llegará a estos esponsales por propios méritos (bc) ${ }^{10}$.

Oria es presentada como mujer aficionada a las lecturas de Pasionarios, en donde conocerá bien los premios y galardones (al menos de los mártires) en el cielo, así como las dos vías para llegar a él: la cognitiva, a través del cumpliento de las "leyes", "razones" y "entendimiento", y la afectiva, de "deleites", "pasiones", "amor e grado a Dios". No debieron resultarle del todo novedosas, por leídas, las propias experiencias de su viaje visionario.

El "aguisar las carnes", la mortificación del cuerpo o maceración a lo divino es la hacienda o dote que aporta Oria para comprar el cielo. Soterradamente parece que el tema de las viandas se mantiene como melodía sorda que va y vuelve en este convite festivo de las bodas, cuya fórmula invitatoria se siente de nuevo en la copla 40d: "Ca Christus te combida" ${ }^{11}$.

10 De las tres guionas, Águeda, Cecilia y Eulalia, parece haber una mayor relación de confianza entre Oria y la santa emeritense, que la trata de "fija" (39a).

11 En el romance de La Sangre de Cristo, se ha mantenido esta idea: "...y le convidó a comer de aquella hostia consagrada, y le convidó a beber de aquella sangre sangrada..."

En el cuento del Cielo y el infierno (recogido a mi abuela materna, Isabel Amieva), que concluía con el refrán: "Axúntate a los buenos y serás uno de ellos, axúntate a los malos y serás uno de tantos", el hombre elige entre dos caminos. El de la izquierda lleva al infierno, donde está el Pecau y hay llanto, fuego y castigo. El de la derecha lleva al cielo, que incluye las siguientes recompensas: No hay vejez, muerte ni tristeza, y sí un eterno "banquete de todo lo mejor; bailes, risas y diálogo con Dios, la Virgen, los santos, amigos y parientes". Tirso, en No le arriendo la ganancia recoge esta misma visión:

Quietud de los ojos míos,

la Sabiduría santa,

que en el valle del Sosiego

reina, virtudes y gracias.

En un eterno banquete,

quiere endiosar nuestras almas.

Cito por Blanca de los Ríos, ed. (Madrid: Aguilar, 1946) p. 659. 
Las tres vírgenes la adelantarán como guionas y "la palomba" será el motor o vehículo para la subida ( 40 bc): "Guarda esta palomba, todo lo ál olvida, tu ve do ella fuere" ${ }^{12}$.

\section{La columna gigante y scala caeli + el vuelo de la paloma}

(Coplas 41 a 46). Se describe una columna enhiesta hasta los cielos (41cd) con escalones o gradas ${ }^{13}$ por donde suben las almas "aventuradas"

También me transmitió la idea del cielo como Corte, verbalizada en la oración final y término del repertorio de las que acostumbraba a rezar por la noche, al acostarse, y con la que también concluía el rosario y las oraciones en tiempo de nube y tormenta: "...A todos los santos y santas de la Corte Celestial, que ellos pidan y rueguen a Dios por nos..... Esta visión coincide en parte con la medieval de Hildegarda de Hilden y la de Gerardesca. Ver Acta Sanctorum, ed. rev. de Jean Carnaudet (París: Palmé, 1866), en el vol. 7, correspondiente al mes de mayo y p. 168. Ver también en R. HerTZ, La muerte. La mano derecha (Madrid: Alianza, 1990). En el capítulo primero de las Vitas Sanctorum Patrum Emeritensium (siglo viI), el joven Augusto es transportado a un locus amoenus y convidado a un banquete. Allí aparecen los santos, coronados en sus tronos y Cristo en otro de mayor aparato presidiendo. Esta concepción del cielo como un mundo material glorificado está muy en la línea de San Ireneo, para quien el hecho de que Cristo tomara forma humana es prueba de que lo humano podía convertirse en divino. Ver la imprescindible obra de Colleen MCDanNELl y Bernard LANG, Historia del Cielo (Madrid: Taurus, 1990), especialmente el capítulo: “El pensamiento de San Ireneo y San Agustín sobre nuestros cuerpos celestiales". Según Ireneo, Dios prepara una mesa para los justos con toda clase de manjares. En suma, a lo largo de la historia del Cristianismo reaparecen tres tipos de cielo: a) el paradisíaco, B) el de los ascetas, de renuncia al mundo, encabezado por San Agustín, que rechaza la idea anterior (fusión de neoplatonismo y dualismo gnóstico), c) el modelo "eclesiástico". Con el reconocimiento y oficialización de la Iglesia, el cielo se convirtió en una comunidad eclesiástica y áulica.

12 Parece haber un cierto paralelismo "al revés" entre nuestra historia y la que se cuenta en el Libro de Alexandre, el vuelo de los grifos que con truco de carne en la pértiga, le guiaban:

Fizo prender dos grifones que son aves..., cuanto ellos volavan él tanto se erguía,

El rey Alexandre todavía sobía,

A las vezes alçava, a las veçes premía.

Allá yvan los grifos do el rey quería.

(Cito por la ed. de Barcelona: Orbis, 1983)

13 En la visión de Perpetua (siglo III) la escala celeste es de oro. Ver en Howard R. PATCH, El otro mundo en la literatura medieval (México: FCE, 1956), p. 99. En el Poema de Santa Oria no podemos saber, al haberse perdido la obra de Muño que toma Berceo, si nos hallamos ante una obra del siglo XI o del XIII. Savonarola, apartándose del cielo tomista, de pura luz intelectual y divina, lo presenta como un ver- 


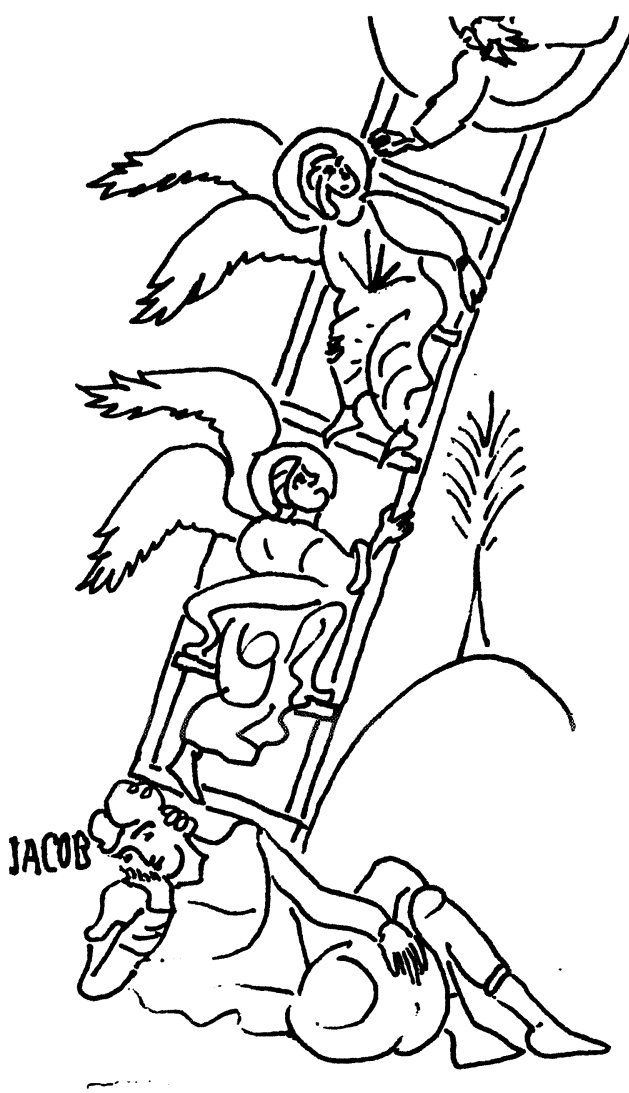

FIG. 2.-Sueño de Jacob en el desierto de Betel. Vio una escala que llegaba de la tierra al cielo con ángeles que la subían y bajaban; en la cima, el Padre Eterno. (Detalle de un mosaico en la Capilla Palatina de Palermo. 1154-1166). Dibujo de A. Cea.
(42), símil que llega a nuestros días divulgado en el canto del rosario y en el refranero ${ }^{14}$. ¿Verbaliza Berceo esta experiencia ascensional, insertando a la mitad de la copla 42 este símbolo que, seguramente, materializaba algún ejemplo de escalera de su propio convento, y deja, a la vez, abierta una posible experiencia personal ascética de itinerarium in Deo, extrapolada al caso de la emparedada Oria? Icono que nos lleva como fuente a la emblemática Escala de Jacob, "aquesta reluzía"(43c), por la que ascendían y bajaban los ángeles que, en vez de emplear sus alas, avezaban al patriarca, cuyas piernas acaban dislocándose ${ }^{15}$.

(Coplas 45 y 46). Las cuatro vírgenes son empujadas hasta la cima de la columna: "puyadas en somo" (45d), "de la columna en somo aplanadas" (46b), donde se cumple la primera jornada de este viaje.

$\mathrm{Si}$ atendemos a lo que se dice en la copla 44, la ascen-

gel al que los santos podían acceder. Todo ello, paraíso y cielo, se conectaba por una escala para los viajeros esporádicos de la tierra. Los santos no permanecían sedentes en rígidas sillas, sino que flotaban sin esfuerzo. (MCDANNELL-LANG, op. cit., y cap. sobre "Los placeres del paraíso renacentista".

14 Una de las estrofas del canto popular del Rosario dice: "las cuentas del rosario son escaleras, para subir al cielo las almas buenas". Como expresión cotidiana y doméstica trae Correas el proverbio: "Escalón a escalón se sube la escalera a mejor mansión". La necesidad de este elemento y medio es recogida en ese refranero cuando dice: "querer subir al cielo sin escaleras [se dice] a cosas imposibles".

15 La idea matriz derivará sin duda del pasaje de la Escala de Jacob (Génesis 28, 10-22): "Viditque in somnis scalam stantem super terram et cacumen illius tangens 
sión a la columna no fue a través de sus escalones, sino por la paloma que porta Oria entre las manos, y guiada por los solos consejos de Olaya, la virgen española (40abc). La copla 44 describe espléndidamente la movilidad, autonomía, intención, autoridad y carrera que inicia la paloma de la santa emparedada que, en realidad, sigue el camino que le marcan las tres guionas, éstas con sendas palomas en las manos (45ab). Quizá el vuelo sin esfuerzo de nuestra santa y no la ascesis, peldaño a peldaño, era gracia de Dios, porque los peldaños ya los tenía con su mortificación día a día ganados ${ }^{16}$.

El árbol sobre el que se posan "estas quatro donzellas, ligeras más que biento" (48a)

De lo alto de la columna suben a posarse ${ }^{17}$ en un árbol de "cimas bien compassadas" (46c), cuyas características son: el estar florido (46d), verde, bien cargado de hojas, frondoso, umbroso y rodeando el tronco de hierba a maravilla $(47 \mathrm{abc})^{18}$, que les proporciona temperatura buena ( $47 \mathrm{~b}$ ), placer y "pagamiento" (48 b), "folgura" (48d) y alegría (49b). Si bus-

caelum, angeles quoque Dei ascendentes et descendentes per eam. La iconografía de la escala como camino del cielo no debía de ser desconocida para Berceo, a través de alguna pintura mural, quizá en miniaturas de algún cantoral o breviario mozárabe. Este pasaje era aún muy popular en los siglos xVII y xvIII, tanto en cuadros de devoción como en libros de carácter piadoso, con títulos como: Camino del Cielo, Llaves del Paraíso, Jornada para el Cielo y jardín florido del alma, Itinerarios del Cristiano para caminar al cielo..., sin duda derivados de otros más antiguos (Ver en A. CEA, "Coleccionismo y devociones domésticas en la Sierra de Francia y Candelario (Salamanca, siglos XVII-XIX)", RDTP, XLVIII (1993), pp. 213, esp. nota 47, pp. 243-244).

16 Mientras el vuelo de las tres vírgenes guionas es una asunción por las palomas que van delanteras, el de Oria parece ascensión — sube sola- o ella lo percibe así; es la sensación irreal de poder y autosuficiencia de los sueños.

17 La agilidad, junto con la sutileza, impasibilidad, claridad, inmortalidad, es uno de los dones y atributos del cuerpo glorioso y resucitado.

18 Berceo, para expresar las perfecciones de éste árbol de copa redonda, simétrico y como trazado a regla y compás, emplea un calificativo propio de las arquitecturas de calidad, como en el pasaje de la sepultura de San Millán, cuya traza en arquisolio define "a siesto compassada" (Vida de San Millán, copla 313 b). Si nos atenemos a lo que hoy se conoce como sabiduría popular y por la calidad de la hierba que crecía bajo ese árbol, tendríamos que concluir que se trataba, probablemente, de un roble, un castaño o un nogal -especies por otra parte abundantes en la riojana sierra de San Lorenzo-, emblemáticos por el buen campo sin maleza, que crían a su sombra. En este sentido trae Correas el refrán: "Sombra de nogal nunca medra"; no deja crecer la hierba mala. Es creencia en Asturias que la madera de la Cruz de Cristo era de nogal y así se tiene por el árbol más seguro para ampararse de las tormentas y centellas, que nunca caerán sobre él. 


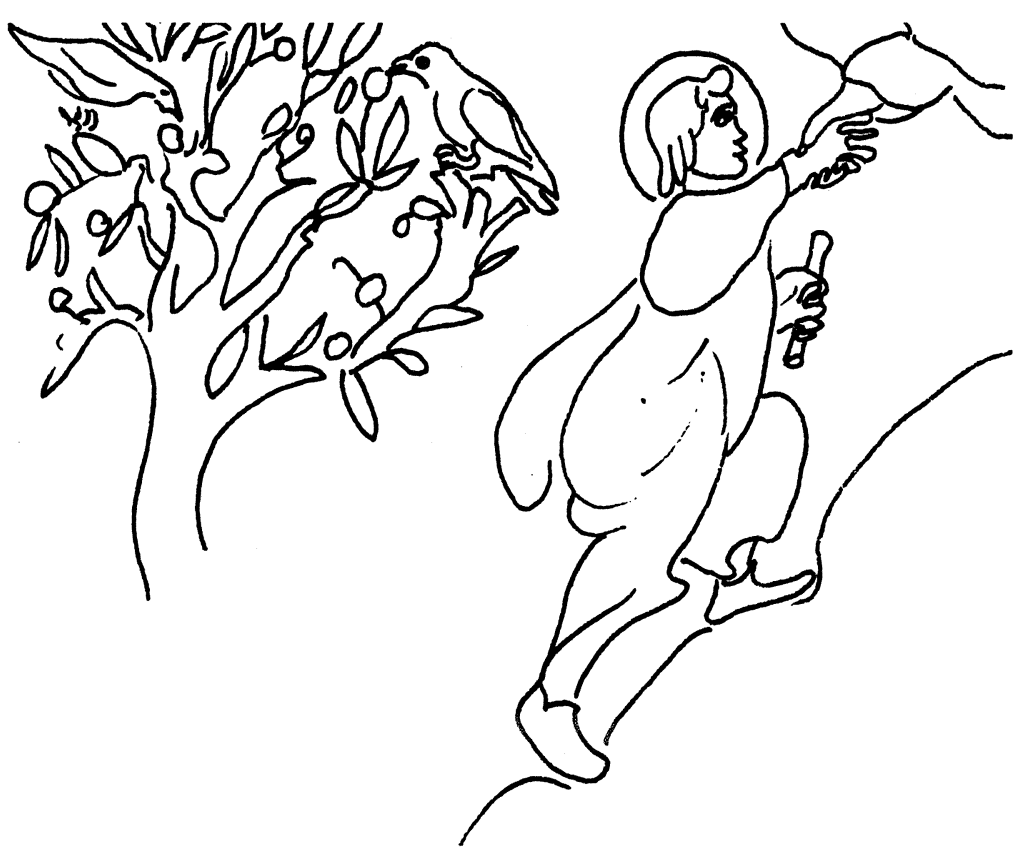

FIG. 3.-Almas-pájaras picando frutos del Árbol de la Vida en el Paraíso + Ascensiónescalada de Cristo desde el Monte Oliveti, al que el Padre da la mano. Milán. Hoja del díptico de marfil de la Ascensión, S. VI (Munich, Bayerisches Nationalmuseum). Dibujo de A. Cea.

caran estas vírgenes bienestar natural habrían permanecido placenteramente a su sombra, pero descansan, no a ras de suelo sobre el mundo infernal, sino en la copa del árbol ¿de la Vida/Cruz? ${ }^{19}$, como almas en figura de ave, en un paradisíaco cielo y primero. Todos los términos irradian materialidad hedonista y natural y la conclusión es de gozoso placer. No se dice cuánto tiempo sosegaron ellas sobre el árbol ${ }^{20}$.

La representación del alma y la inmortalidad como ave y paloma en distintas actitudes sobre el árbol de la Vida es un topos universal: picando de sus flores y frutos, reposando o en posiciones voladoras, afrontadas, tenantes, recelosas (indistintamente de que aparezcan representadas

19 Una de las coplas que se canta en la novena del Cristo del Camino (Llanes) -fiesta que se celebra el 16 de julio, o Exaltación de la Cruz- juega con ese doble concepto: Árbol de la Vida/Cruz. "Árbol de la Vida, cuyo fruto dio vida, que otro fruto [la manzana de Eval la vida quitón.

20 Para Cirlot, el árbol es eje entre dos mundos. Conduce una vía subterránea hasta el cielo, y se corresponde su asimilación a la escalera o montaña, como símbolo de relación entre los tres mundos. 
con una concepción naturalista $\mathrm{o}$, por el contrario, adopten una manera esquemática y hierática ${ }^{21}$ ).

En el mundo cristiano occidental la iconografía prototipo de la paloma se utiliza para representar la figura del Espíritu Santo y, en consecuencia, de la Gracia por asociación con esta tercera divina persona. La paloma, además, aparece como heraldo de las embajadas angélicas, augurio fasto, signo y sello de la inspiración celestial y de la teofanía, posándose sobre las cabezas y hombros de los santos y elegidos, o como su principal atributo. También y por la misma asociación trinitaria simboliza la resurrección y la gloria tras la muerte, saliendo como paloma el alma de la boca del justo.

Así se canta en la copla 600 de Los Milagros de Nuestra Señora (cuento 22 , "El náufrago salvado"):

Vidieron palombiellas essir de so la mar, más blancas que las nieves contra'l cielo volar; credién que eran almas que querié Dios levar al sancto Paraíso, un glorioso logar.

Por el contrario, en el arte bizantino, el alma se representa como un niño en fajas que transportan al cielo los ángeles o el propio Cristo, en el tema omnipresente de la Dormición o Tránsito de la Virgen, de donde deriva a la escultura funeraria medieval europea ${ }^{22}$.

${ }^{21}$ La representación del árbol de la Vida con animales afrontados a los lados -leones, perros y aves o "pájaras" - ha pervivido en numerosas piezas-testigo del arte popular (derivando, quizá, de motivos suntuarios medievales) en soporte de madera, piedra, asta y textiles (encajes y bordados), de manera llamativa en el área del Noroeste peninsular.

22 Michel PASTOREU - Couleur, images, symboles. Études d'histoire et d'antropologie (Paris: Le Lèopard d'Or, [s.a]) en el epígrafe "le bestiaire de la Vierge et des Saints", pp. 105 y ss.- afirma que es prácticamente inexistente el bestiario como simbología mariana antes del siglo XIV, momento de la "heraldización" definitiva de las imágenes, donde el animal no puede tener parte. Tímidamente aparece la abeja como símbolo de la virginidad por su partenogénesis [Recordemos, de todos modos, este atributo en la advocación de la Valvanera, aunque desconocemos cuándo se incorporó el panal a esta iconografíal. Comenta Pastoreau: "Toutefois, en matière de bestiaire, le couple Vierge-Ecclesia peut être raproché du couple Père-Fils, du moins à partir du $\mathrm{III}^{\mathrm{e}}$ siècle. En tante qu'elle évoque l'Église, qu'elle l'incarne ou qu'elle se confonde avec elle, la Vierge peut en effet être dotée d'animaux symboliques: parmi eux, la colombe est celui qui revient le plus souvent; elle s'oppose alors dans le rôle à la Synagoge. d'où cette distinction: lorsqu'elle est mère du Christ, la Vierge, comme le Père, est déporvue de bestiaire: lorsqu'elle est en revanche épouse du Christ, elle accède au champ animal" (el subrayado es mío). Supongo que querrá decir el autor «esposa del Espíritu 
Las palomas - motores de nuestras tres guionas Águeda, Cecilia y Eulalia- podrían estar representando a sus propias almas, como la de Oria, escapada de su cuerpo para esta visión. Como observa Guiance, la exhalación del alma es un recurso constante en la muerte de los santos; situación de la que los textos evangélicos dejan muchas lagunas. En las actas de la muerte de Santa Eulalia de Mérida (S. VII), una de nuestras protagonistas, se dice que "una paloma, saliendo de su boca voló al cielo" ${ }^{23}$.

Santon y no de Cristo. Recordemos que respecto a la Trinidad, María viene titulada como: "Hija del Padre, madre del Hijo y esposa del Espíritu Santo".

23 Ariel GuIANCE, Los discursos sobre la muerte en la Castilla Medieval (ss. VII-XV) (Valladolid: Junta de Castilla y León, 1998). Ver especialmente el capítulo: "El más allá", pp. 131-231, basado prácticamente en su anterior artículo; "Sobre el espacio y el tiempo en la literatura castellana medieval", Temas Medievales, monográfico sobre: Tiempo y Memoria en la Edad Media (Buenos Aires, 1992), pp. 137-158. Ver, España Sagrada, XXIX, p. 374 y Patrología Latina, LXXXVII, col. 1099. En Giuseppe GATTO, "Le voyage au Paradis. La christianisation des traditions folkloriques au Moyen Age", Annales (ESC), 5 (1979), pp. 929-942. En Claude CAROZZI, Le voyage de l'âume dans l'au-delà d'aprés la littérature latine ( $V^{*}$-XIr siècle) (Roma: École Française de Rome, 1994), p. 60. En las Vitas Sanctorum Patrum Emeritensium (s. VII), cuenta San Valerio en la narración $4^{\mathbf{a}}$, cómo el cantero Baldario percibe que su alma es recogida por tres palomas que la llevan ante la Majestad divina. En el viaje de Máximo son también tres palomas brillantes las que transportan el alma de dicho Baldario: aex quibus una super caput Christi gestabat vexillumw.Ver en Manuel DíAz y DíAz, De Isidoro al siglo XI. Ocho estudios sobre la vida literaria peninsular (Barcelona: El Albir, 1976). Resplandeciente se canta el alma de Cristo en el Ramu del mencionado Cristo del Camino (Llanes):

No murió el Señor

porque está en la Gloria

tan resplandeciente

como una paloma.

En la misma villa asturiana (14. ${ }^{\text {a }}$ Carrera a la fuente, en la fiesta de la Salea) y con el mismo símbolo se identifica al Espíritu Santo:

De la mar vengo, Señora,

traigo aquí dos blancas palomas,

figura del Espíritu Santo,

bajadas son de la gloria.

Ver A. CEA, La Canción en Llanes (Salamanca: Calatrava, 1978), p. 27.

En la visión de Alberico, la paloma hace también de guiona (Howard R. PATCH, $o p$. cit.). Las mismas esencias recoge Cirlot, ideas que, según él, se manifiestan de manera especial en la iconografía visigoda y románica. La paloma participa del símbolo de todo animal alado: espiritualidad y sublimación. Como señal divina del designio celestial aparece en el tema de los Desposorios de la Virgen, refiriéndose a San José como el pretendiente escogido: “...y cuando hubo llevado su vara, y en su extremidad reposó una paloma venida del cielo, todos [los demás pretendientes a la mano de la Virgen] convinieron en que a él le pertenecía de derecho desposar a María" (Evangelio de la Natividad de María, VIII, 1). 
Las tres ventanas del cielo y castillo celeste, bajada de los ángeles + las cuatro asunciones

Vidieron en el Cielo finiestras foradadas, lumbres salién por ellas...

Incluye aquí Berceo (coplas 49cd a 54a) como melodía menor, solo esbozada, el tema del "palacio labrado a la maravilla". Visión que, desde la copa del árbol, tienen las cuatro vírgenes de un primer cielo/castillo trifinestrado, de cuyos vanos, como si de una tramoya se tratara, salen tres ángeles mancebos, peregrinos voladores, pormenorizadamente descri-

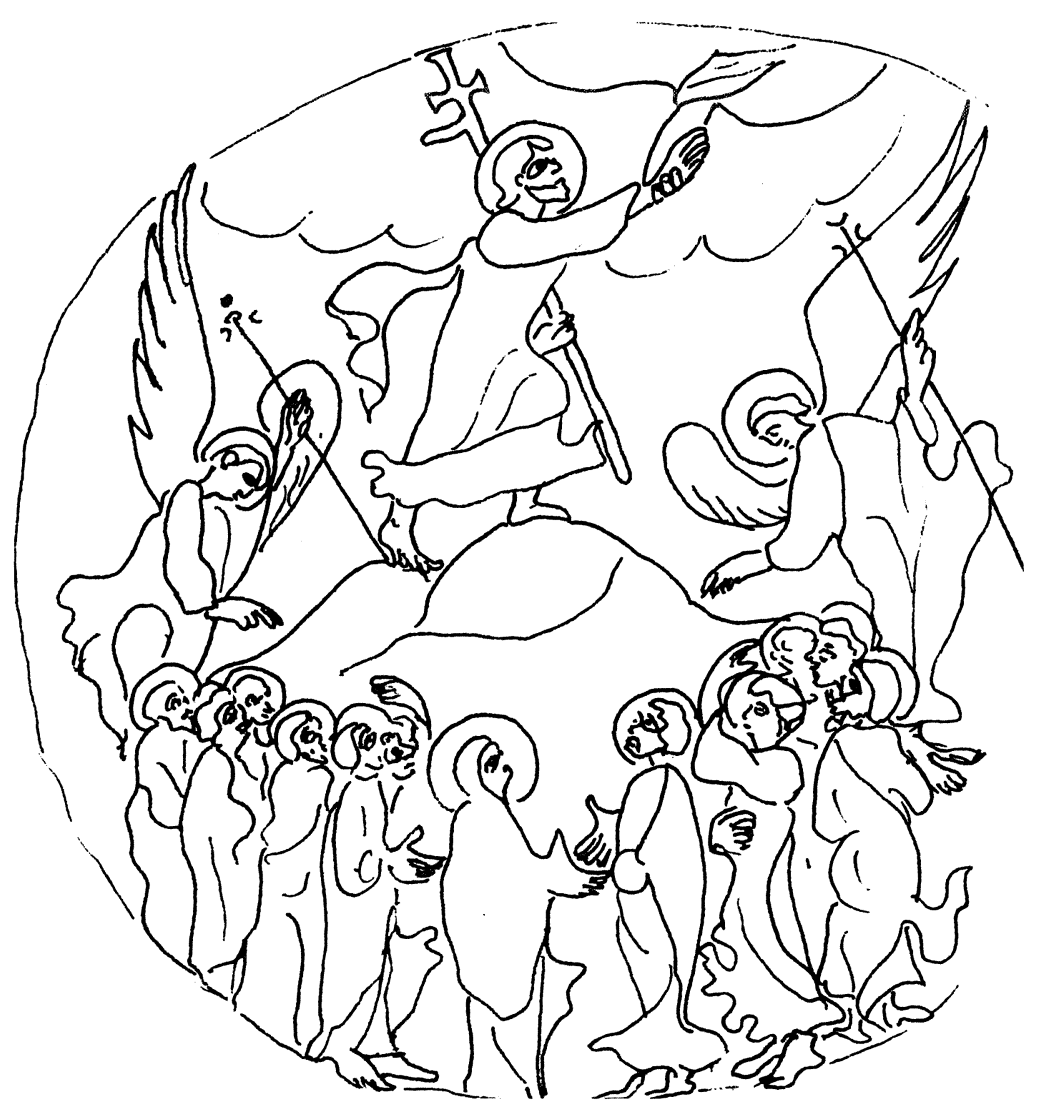

Fig. 4.-La Ascensión desde el Monte de los Olivos en presencia de María y los apóstoles. Dos ángeles portan los "blagos" que menciona Berceo para subir las almas. Metz, Sacramentario de Drogon, 807-855 (París. Biblioteca Nacional). Dibujo de A. Cea. 
tos, al igual que su actitud y actuación: Tienen forma humana (50d), llenos de luz (49d) con vestidos blancos (50b) y una verga o bordón en cada mano "de preciosas pinturas" (50c). Con un lenguaje solo gestual, sin parlamentos (51) suben a las cuatro vírgenes sobre aquellos bordones, a manera de cambas de carro y vuelan tan ligeras como si fueran plumas (51b). Oria, que va en cuarto lugar, sigue, al mismo tiempo que es transportada sobre aquel artefacto - bien advertida por su virgen confidente: "Como la ovo ante Olalla castigada" (52b)—, sin perder con la vista a su paloma guiona $(52)^{24}$.

Se sobreponen en este pasaje varios vehículos y transportadores celestiales que, sin llegar a contradecirse dejan al observador un tanto extrañado: las vírgenes (Eulalia, Cecilia y Águeda), sus palomas, los ángeles y sus bordones, más la paloma de Oria. Todo esto cuando se afirma, además, que Oria: "Puyaba a los cielos sin ayuda ninguna" (53a).

Esta tercera jornada ascensional termina con la llegada a una "grant posada" (52d). "Pusiéronlas [los ángeles] más altas, en otras regiones" [sic.] celestiales, desde donde presenciarán "muchas honradas procesiones" (51d) de las distintas jerarquías de santos, cuyos raseros se establecen según la medida de virtud que labraron en sus vidas terrenales. En función de esa distribución y ordenamiento se desarrolla la liturgia celestial a la que asistiremos en la cuarta jornada, que tiene lugar a continuación.

\section{VISIÓN DEL CIELO Y PASEO POR ÉL}

Entraron por el Cielo que avierto estava

alegróse con ellas la cort que y'morava... (54ab)

(Coplas 54 a 100). Se inicia esta visita de Oria, apellidada aquí, no parece que al azar, como "essa serranilla" (54d), pues anticipamos que su curiosidad por los personajes celestiales parece focalizada exclusivamente hacia una pueblerina identificación de paisanaje, sirviendo siempre de anfitrionas las tres mencionadas vírgenes ${ }^{25}$.

24 El Canto XXIX de la Divina Comedia de Dante: "Floresta divina. Procesión simbólica" recuerda bastante a nuestro pasaje cuando dice:

$$
\begin{aligned}
& \text { (106-108) Encuadran un espacio que contiene } \\
& \text { un carro, con sus dos ruedas, triunfal, } \\
& \text { que un grifo a la cerviz atado tiene... } \\
& \text { Tres mujeres danzaban suavemente } \\
& \text { junto a la rueda diestra... }
\end{aligned}
$$

[Sigo la edición, con traducción, introducción y notas de Ángel Crespo (Barcelona: Planeta, 1990), p. 366].

25 Ver tabla de apelativos con que se nombra a Oria, donde solamente aparece cuatro veces el de "serranilla" o "serrana". 
En una atmósfera distendida y nada exclusivista — las puertas estaban abiertas, eludiendo la figura folklórica del guardián o clavero San Pedro ${ }^{26}$ se encuentra con una concurrencia calificada como "cort moradora" (54b), a la medida terrenal de su tiempo, que, en gesto muy humano, manifiesta alegría por su llegada ${ }^{27}$.

\section{Calonjes o confesores, primera e inferior jerarquía}

Ante los ojos de la santa emparedada aparece un "muy gran compaña de calonges" (55a y 57b) con vestiduras albas (55b), que compara con "las flores de mayo" (56d), pero cuya iconografía no llega a reconocer: "Dezitme qué es esto, por Dios e San Pelayo" (56b) ${ }^{28}$. Las tres vírgenes que tratan, ahora sí, a Oria de "fija querida" (57a) le dan contestación: "calonges fueron éstos, omnes de sancta vida" (b). Sí entresaca de entre aquella mesnada cuatro personajes que le resultan familiares: a Bartolomeo, experto en Pasionarios (58c) -inventor o escriptor de historias de santos- como probable lectora de su obra y personaje relacionado con el monasterio y, por alguna razón, cercano a ella. De los tres restantes, sin haberlos visto nunca, tiene interiorizada ala especie" y, por razones de paisanaje ("les habrá oído mentar") los identifica: Son, Don Gómez de Massiella, "que dava bien raciones" (58d); el hidalgo Don Xemeno, vecino de Villavellayo (59ab) y Galindo, su criado (no desaparece en el cielo el papel de vasallaje), también paisano suyo.

Queremos subrayar con este pasaje la utilidad de la buena transmisión oral como criterio de autoridad, capaz de lograr indeleblemente una figura mental, sólo por lo que se ha oído contar, hasta hacerla reconocible entre una muchedumbre: "conosció [...] los que nunca vidiera..." (58ab).

26 Aparecen los cielos abiertos de par en par, tal y como los vió el protomártir Esteban en su martirio: "video caelos apertos" (Hechos 7, 55-56), inclinándose Berceo por esta fórmula, en lugar de la más restrictiva y folklórica que conlleva el vigilante papel de San Pedro, oficio que sí se muestra en otro pasaje del Poema, aunque desempeñado por un personaje femenino.

27 No creemos que utilice aquí Berceo el término "morador" en sentido estricto, de situación transitoria - tal y como usualmente se entendía en su tiempo, y contradictorio, aplicado a unos personajes que habitan eternamente el cielo-, y opuesto al de "vecino", que es el que realmente conviene aquí; quizá se deba a exigencias métricas.

28 Es recurso y muletilla muy socorrida en el romancero (vg. en el romance de Jesucristo iba de caza...) el binomio: "Por Dios y Santa María", que aquí es sustituida, quizá por imperativos métricos, por ese santo, galanejo y mártir, tan venerado en La Rioja. 


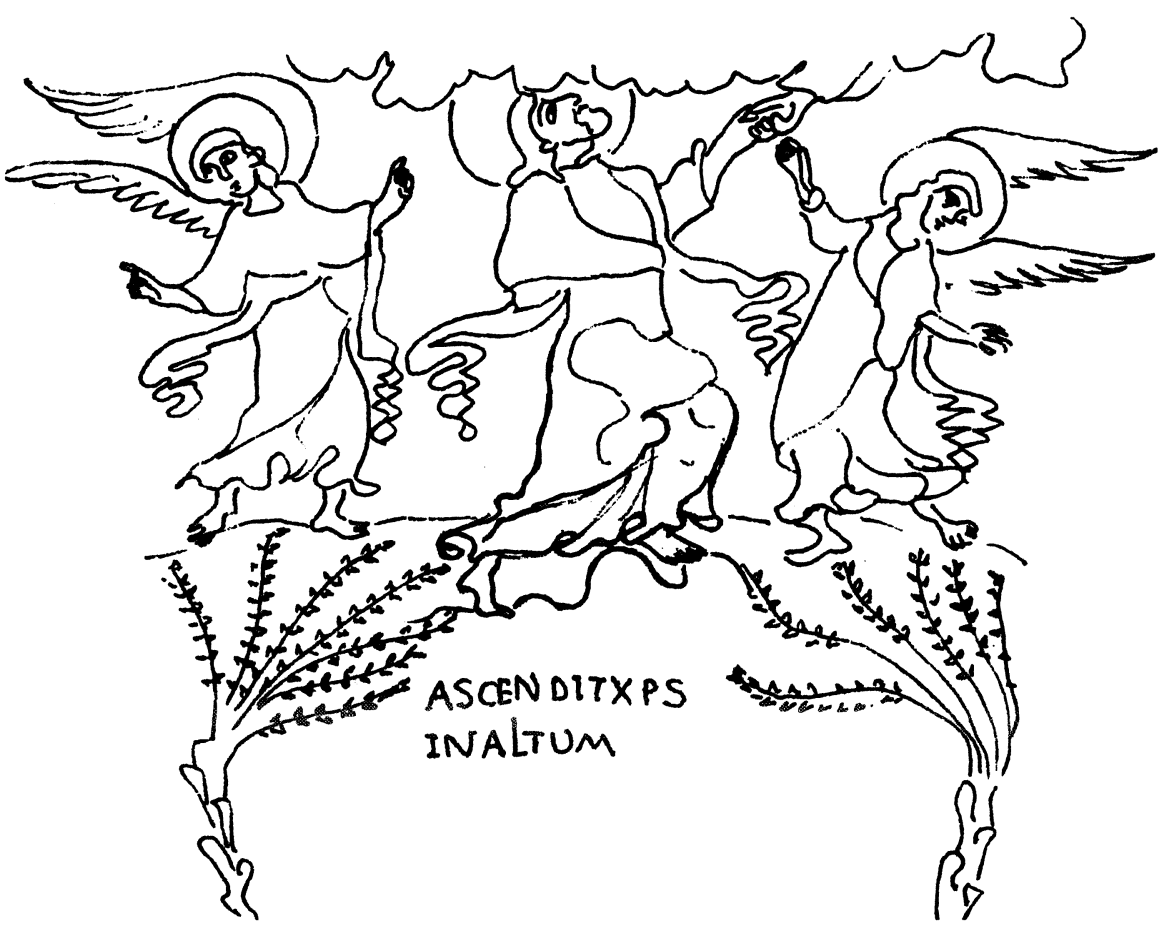

Fig. 5.-Ascensión de la Biblia llamada de San Pablo Extramuros iproc. de S. Denis? Siglo X. Cristo es acompañado por dos ángeles desde el Mons Olivarum y recibe ayuda, entre nubes, de la mano del Padre. (Dibujo de A. Cea).

Como galardón logra aquí Oria el placer de la identificación, aunque no la empatía; no se dice que estos personajes gestualicen ni que ellos la vean a ella. Queda satisfecha la curiosidad de la reclusa, que los disfruta como niño ante un escaparate.

\section{Segunda escala o jerarquía de obispos}

Yendo más adelante en esta visita celestial, denominada ahora "romería" (60a) y siempre guiada por las tres mártires, llegaron junto a una segunda jerarquía - muy mejorada - que Berceo califica como ugran compañía" (60c), "sancta mesnada" y "convento" (66a), donde los personajes, obispos, no se describen con una gestualidad congelada, sino en el movimiento de una "gran" y "preciosa procesión" (62b). Iconografía o perfil que tampoco parece reconocer nuestra santa tocanegrada, a cuya pregunta responden las tres guionas: "Obispos fueron estos" (62d). Pasa Berceo 
a describir pormenorizadamente sus insignias episcopales: "casullas de preciosos colores", "blagos en las siniestras, como predicadores", "cálices en las diestras" (61abc). Curiosamente, se elude el elemento prototipo identificador de su grado supremo sacerdotal, salvo de pasada, en la alusión a Don Gómez, única figura de la que se dice: "que traxo mitra" $(65 \mathrm{c})$, y a quien Oria en este viaje en vano esperaba ver y reconocer. A este desencanto responden las guionas: " tal fue como el árbol que florez e non grana" (65d); es, pues, una contrafigura o anti exemplum y árbol valdío en el hortus de la Iglesia, al que Berceo aplica el caso maldito de la maldita higuera-estéril evangélica ${ }^{29}$. Además del perfil iconográfico se da, quintaesenciado, el papel catequético de los obispos hacia su grey: "Porque daban al pueblo bever de buen castigo" (63a) ${ }^{30}$.

Queda Oria deslumbrada por el esplendor material en el atuendo de aquel grupo de eclesiásticos y así lo manifiesta: "semejaban ministros de preciosos señores» (61d). Una vez más, la corte del cielo de la que Cristo es rey aparece trazada a la medida terrenal.

\section{Tercera jerarquía: el coro de vírgenes}

(Coplas 66 a 79). Berceo, adaptándose al mundo cognoscitivo de Oria, interpreta el tránsito de la jerarquía de obispos a éste de las vírgenes solo como el paso de una comarca a la siguiente vecina, que era como sentirse en casa (66b): un "coro de az muy luenga" (66c y 79 ), "fermosa az" (70a). La disposición de este tercer coro es de "procesión honrada" (66c), y la actitud, de simpatía exteriorizada en forma de "recebimiento" - situación que se expresa tres veces (66d, 67a y 68a) - y gestos afectuosos: "Con los brazos alçados", de manera interactiva, la abrazan (67b) y cantan alegres: "con responsos doblados" en octava (67a).

Este repertorio de gestos, que tan de cerca nos recuerda los alborales a la novia de compañeras y amigas, la noche anterior a la boda ${ }^{31}$, culmina con un Paxtecum de todas y por orden (70b).

29 Aparece en Mateo; 21, 18-21 y Marcos; 11, 12-14, 20-24.

30 Isabel Uría interpreta este hemistiquio como una figura de la comunión sacramental bajo la especie de vino (ver nota 63 de su edición, p. 514). Nos inclinamos a pensar que se trata más bien de un pasto bebedizo o exemplum como se concreta en el verso 63 c: "refirién en los cuentos al mortal enemigo"... El engaño de la Serpiente a Eva, aquí mostrando un "astroso figo" (d) en vez de la manzana. Todo ello viene a corroborar la importancia de la narratio en los sermones.

31 De las variantes de alborales o alboradas que conocemos en los pueblos de la Sierra de Francia (Salamanca), damos una de las estrofas que se cantan en Miranda del Castañar: 
Contrariamente a lo que ella esperaba, no pareció recibirla su Maestra Urraca, ni su condiscípula Justa, ¡lo que ella más deseaba! y a la que solo le es permitido oir. La hipercaracterización de empatía es compensada con la ausencia de descripciones identificatorias iconográficas, innecesarias al pertenecer Oria a este coro de virtud.

Las coplas $68-69$ y 72 perfilan el impacto de este recibimiento, según ella inmerecido. Queda confundida, siente vergüenza, rubor y aturdimiento pero, a la vez, un gozo nuevo y desea permanecer en ese estado y compañía. Verbaliza el tema de los Desposorios Místicos con Cristo (en cuya lista iconográfica debemos incluirla): "mas el nuestro Esposo, a quien voto fiziemos, fízonos esta gracia porque bien lo quisiemos" (71cd).

Finalmente (coplas 72 a 79) tiene lugar el reconocimiento entre las de este coro - como ya anticipamos- de su Maestra Urraca. Sus compañeras llaman a Urraca y ella responde, invisible, con su voz.

"En cabo de las vírgenes, toda la az passada" encontró su silla, como en un paréntesis al que luego se vuelve (80a).

Cuando después de su muerte tome definitiva posesión de esa silla, ila situará en la jerarquía de las vírgenes o precederá con ella a la de los mártires-inocentes, entre los que, parece, Oria se instala? (como luego se verá).

\section{Cuarta escala: apartamiento de ermitaños}

(Coplas 83-85). Se define esta jerarquía, que no sabemos si estaba centrada en dos haces, o lateralizada, como un "apartamiento", "precioso combiento" y "compañía" (83ab). No se dibujan las actitudes iconográficas, atributos, indumentaria ni gestualización de estos personajes. Como viene siendo habitual, la curiosidad localista de nuestra santa le lleva, no a identificar figuras emblemáticas tan populares en este caso como San Antón o San Pablo ermitaño, sino a pararse en nombres por alguna razón familiares. Es el caso de Monio, prior que fue del eremitorio de San Martín de Cañas, filial de Valvanera, Muño, abad de ese monasterio, Galindo, muerto en su ermita por unos ladrones, y su propio padre "que llamaban García" (85c), con el que no intercambia ni parlamento ni gesto de cariño y, no sabemos por qué, clasificado entre los eremitas ${ }^{32}$.

Porque te vas a casar

tus primas y tus amigas

hemos llegado a la puerta

a darte la despedida [al abandonar la casa paterna]

32 En la nota 85 a de la ed. de B. Dutton de 1981 , p. 127 , se habla de dos posibles Garcías: el padre de Galindo y el de la propia santa. De ser el de Oria chabría que suponer que acabó sus días como eremita en Suso? 


\section{Quinta jerarquía: los mártires}

(Coplas 86-88). Señalando la mayor altura y dignidad de este coro "escontra esquilón" (86a) vio "grandes compañas" y "fermosa criazón" de mártires (86b y 87b), cuyo único atributo es el color de sus ropas, teñidas con la sangre del Cordero: "vestidos todos de vermejón" (86c). Jerarquía que tampoco acierta a identificar Oria: "Éstos ¿qué cosa son" (86d). A lo que responden las vírgenes guionas: "dexáronse matar, por ende Jesuchristo diolis ricas coronas" (87cd); atributo que no aparece aquí exteriorizado, sino internalizado.

Oria suele reconocer y separar de entre los haces de santos un tetramorfos de personajes que aquí son: San Sebastián, "apedreado", San Lorent, "asado", San Vicent, "el caboso" y San Valerio, "Su criado" y "buen lego" (87abcd). Aunque no son coetáneos de Oria, sí son los cuatro venerados en la comarca riojana y por tanto, dentro de esa tónica de paisanaje, aquí topo-hagiográfico ${ }^{33}$.

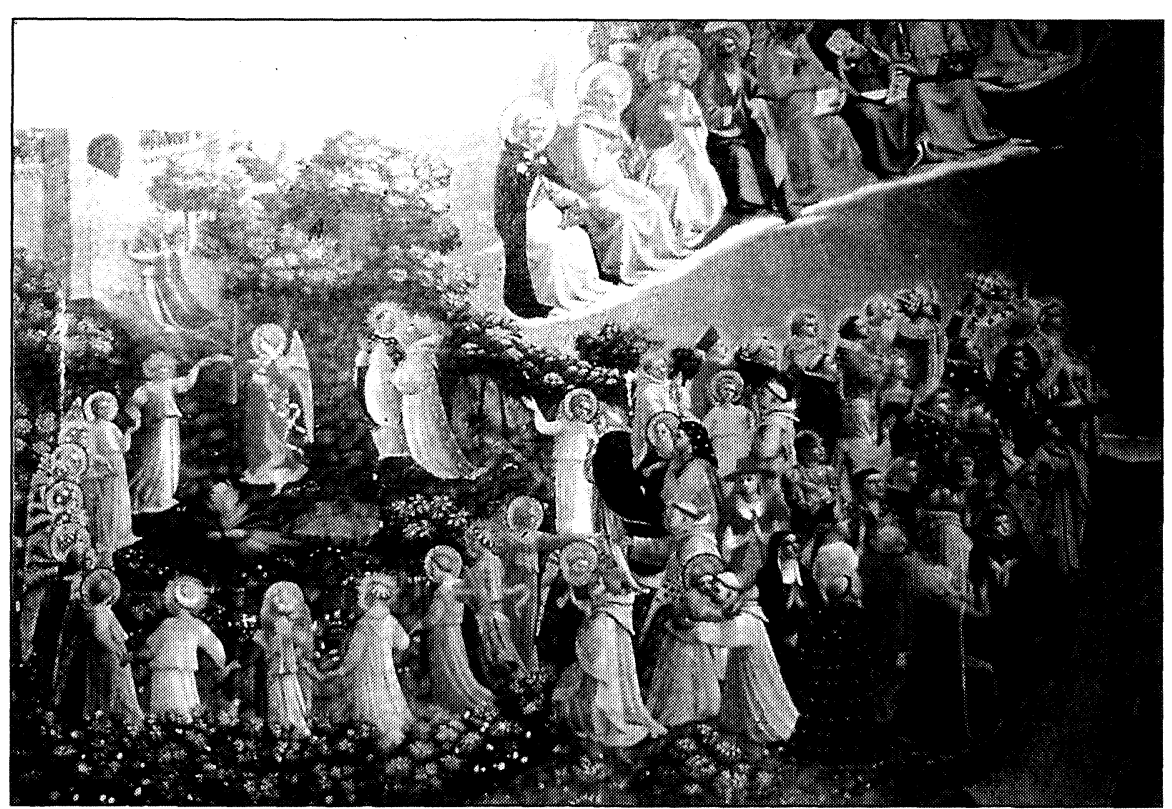

Fig. 6.-Danzas y saludos entre ángeles y santos en el Paraíso. Fra Angélico, Juicio Final, c. 1430, detalle (Monasterio de San Marcos, Florencia).

33 Las razones hagiográficas por las que van asociados estos santos y las de su culto en La Rioja quedan explicadas con todo pormenor en la ed. de Dutton, op. cit., pp. $142-144$. 


\title{
Escala sexta: los apóstoles y evangelistas
}

(Coplas 89-90). La jerarquía de este coro aparece "más en alto logar". Su atributo, la "claridad inefable" y su posición, "cascuno en su trono, en que devié juzgar" (89bd). En realidad está presentando al apostolado, tal y como se pinta en la iconografía del Juicio Final. Aunque Oria los percibe con gestos de autómatas en descanso, están en actitudes anticipadas de llegar algún día a juzgar las almas.

Nuestra tocanegrada no hace preguntas sobre este grupo que ve en su paseo, y que ahora sí parece identificar, ni siente curiosidad de paisanaje; no hay ningún conocido cercano por quien preguntar.

Esta jerarquía, ponderada aquí como suma o suprema, manifiesta unas ciertas características o adherencias de élite -clerical y secular-, articuladas a la manera de la sociedad contemporánea de Berceo.

La denominación de cardenales con que se identifica a evangelistas y apóstoles tiene un evidente color anacrónico que contamina, al menos desde los siglos XIV y xv, la representación iconográfica de algunos de ellos, de posición social y profesional privilegiada, como es el caso de los evangelistas Lucas y Mateo, con indumentaria de médicos y con anteojos, o la del propio San Jerónimo, uno de cuyos atributos con que se identifica es el capelo y demás ropas cardenalicias.

Ellos manifiestan sus atribuciones y cualidades en la copla 90abcd: Aparecen como nuestros padres, y "cabdiellos generales", "ombres principales", "cardenales", desterradores de los pecados del mundo y como los doce pilares de la Iglesia.

Con el encuentro de la silla y su guardiana concluye su paseo por las jerarquías celestiales, sin llegar nunca a las angélicas ni a la presencia divina directa, por más que el esposo, "Don Cristo", y Oria, su prometida, se hablen sin verse, como a través de un torno conventual.

\section{Aún no es tiempo de gloria ni esponsales}

\author{
Non puede seer esto, Oria, esta vegada; \\ de tornar as al cuerpo, yazer emparedada, \\ fasta que sea toda tu vida acabada. (100bcd) \\ ... torna a tu casiella, reza tu matinada. (110d)
}

(Coplas 100-110). Este es el final del parlamento de Voxmea, que llena de desencanto el alma de Oria al ver pospuestos el logro del cielo prometido y la silla como lugar de gloria y esponsales. Pasaje que rezuma ailia, anticipada en varios actos, con que acaba esta primera visión. 
Describe Berceo a la guardiana de la silla de Oria como "bien razonada" (100 a). En sus palabras está la cordura venciendo a la visión, la ilusión y el deseo. Es el neti neti hindú, el "todavía no"; "tornar has al cuerpon y yacer de nuevo emparedada hasta el fin de la vida. Queda bien claro y manifiesto que ha sido solo un viaje del alma. Voxmea hace luego mutis.

Suplica Oria la intercesión de sus vírgenes guionas para permanecer con Voxmea y concreta la petición bajo la fórmula: "al rey de Majestat" (102 b). Ellas, en cambio, "rogaron a $\operatorname{Dios}(103$ a). ¿Si hubieran rezado a Dios como rey relacionando las voces SILLA / TRONO, habría atendido la petición y no hubiera tornado Oria a su celda?

No bastó la buena voluntad de las tres vírgenes, Eulalia, Cecilia y Águeda, acompañada de una fórmula petitoria inadecuada, oración vocal que no verbaliza Berceo, pero sí manifiesta los malos resultados: oraron: "quanto mejor sopieron", "mas lo que pedié ella ganar non lo sopieron" (103ab).

La copla 104 refleja la taxativa respuesta de Dios a las vírgenes, que le oyen pero no le ven: "Piense Oria de ir a su lugar", que lacere más su cuerpo. Tiempo vendrá de ocupar la silla y habitar el cielo. En los versos $98 \mathrm{~b}$ y $106 \mathrm{c}$ aparece esa herencia divina calificada como "Solar".

Las coplas 105 a 110 se llenan con el parlamento entre Dios y el alma de Oria, que se entromete en la conversación anterior. Echando mano de resortes angélicos ${ }^{34}$, llamándole Señor y Padre (106a) — grados de parentesco ficticio y transposición a lo divino de los vínculos señoriales- obtiene una respuesta generosa. Queda patente la importancia de la destreza en la oración a través de la humildad, seguramente aprendida en su monasterio de Suso, manifestándose como "pecadriz mezquina" (107a) y expresando el deseo de alcanzar la gracia (106b) por medio del laceramiento que gana el amor divino (108cd).

Dios responde a la sabia oración de Oria devolviéndole el mismo tratamiento: "la mi fija querida", "mi fija benedicta vayas e santiguada" (109c y 110c); es la fórmula del vade in pace.

"Don Cristo" como arquitecto divino mudará para ella la subida a los cielos: "Lo que tú tanto temes [...] que los Cielos son altos, enfiesta la subida, yo te los faré llanos, la mi fija querida" (109) ${ }^{35}$.

34 Sabía bien Oria la fórmula más adecuada de la oración para ser atendida por el Padre: Mateo; 6, 5-15 y Lucas; 11, 1-4.

35 La fuente aparece en Mateo; 3, 1-3, Marcos; 1, 2-3, Juan; 1, 2-3 y, más explícitamente, en Lucas; 3; 3-6. El pasaje evangélico de San Juan Bautista donde insta a preparar la llegada del Mesías, haciéndose eco de la profecía de Isaías (40, 3-5), cuando dice: "todo barranco se rellenará y todo monte y collado se rebajará; y lo tortuoso se 
a) La bajada

Las tres mártires sanctas ${ }^{36}$ que con ella vinieron, en ninguna sazón della non se partieron, siempre fueron con ella, con ella andidieron fasta que a su casa misma la aduxeron (101)

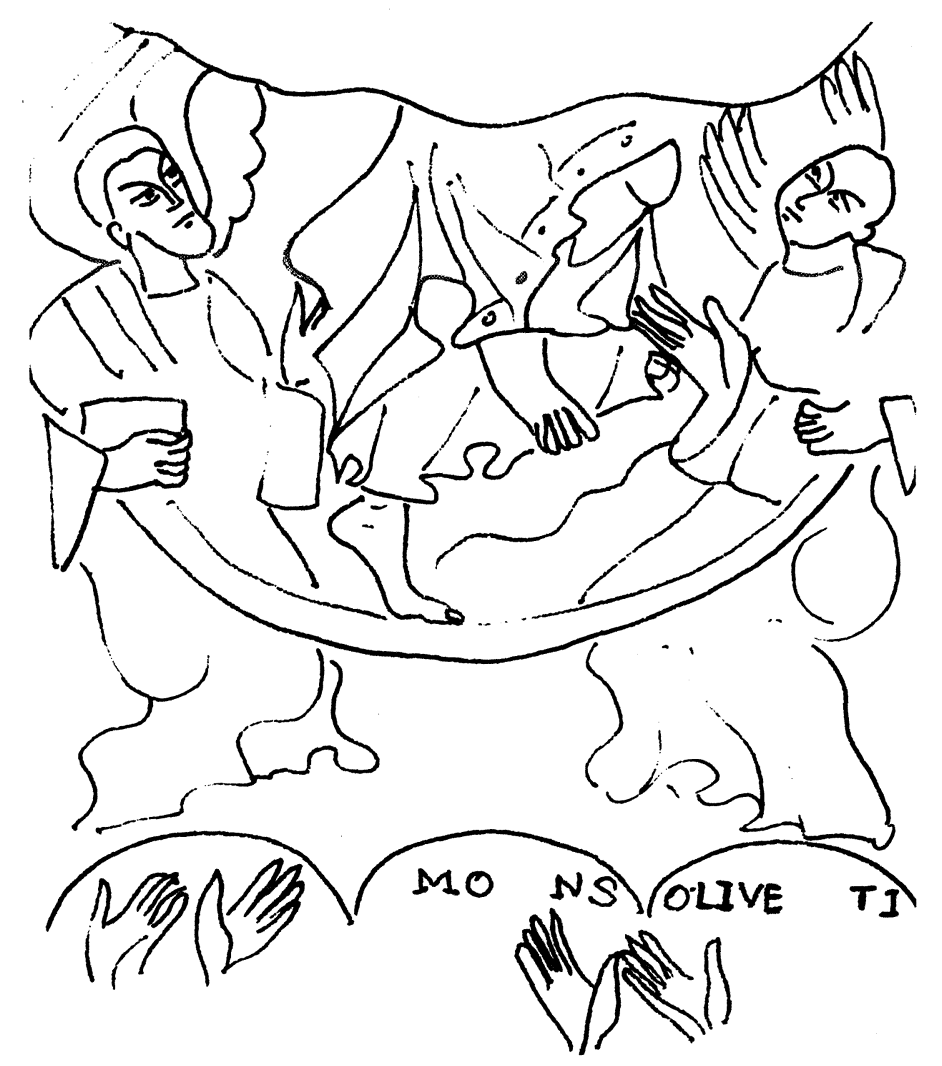

FIG. 7.-Ascensión de Cristo. Tropario procedente del sur de Inglaterra. S. XI (Londres, British Museum). Dibujo de A. Cea.

hará recto, y lo áspero, caminos llanos"... es reutilizado por Berceo poniéndolo en boca del propio Padre Eterno, que hace aquí de caminero divino, preparando el de Oria al cielo.

36 Las santas guionas, Eulalia, Águeda y Cecilia aparecen nombradas como "vírgenes" nueve veces (versos 30a, 32a, 33a, 35a, 46a, 51 a, 76a y 87a), siempre encabe- 
Oria es bajada por la misma escalera por donde la subieron (111a), "en muy poquiello rato al cuerpo la tornaron" (111c). Curiosamente, en el viaje de vuelta a la tierra no aparecen las palomas como divinos motores.

Para expresar la vuelta del alma al cuerpo utiliza Berceo el verbo "espertar" (11d), en lugar de "recordar", voz con la que suele indicarse el paso normal y cotidiano del sueño a la vigilia.

b) La vuelta a la penitencia diaria

(Coplas 112 a 115). La copla 112 describe magistralmente la sensación de desencanto de Oria al abrir los ojos y mirar alrededor, ya sin el constante apoyo referencial de las tres guionas, lo que le produce un estado de pozos y ailía que siembra de dudas e intenciones las coplas 114-115: deseo de volver a la celestial compañía, dolor por verse apartada de la silla y miedo de perder ese galardón, mortificación corporal y "baticores" - pálpitos por todo esto- (116c).

c) El divino esposo y el alma enamorada

(Coplas 116 a 118). A los once meses del primer viaje celestial Dios le prepara, por gracia, otro nuevo. Aún no había olvidado Oria la celestial compañía cuando por segunda vez "vido gran visión" (118a). Pero ahora no pondrá Berceo el corazón de la emparedada en la silla, sino en Dios.

Los versos $118 \mathrm{~cd}$ pregonan el mutuo amor entre Dios y Oria y son dignos de la iconografía de la santa abadesa Gertrudis la Magna, sobre cuyo corazón reina un Jesús infante y el lema: in corde Gertrudis invenietis me", pero en el Poema, al revés: "non se partié Dios della en ninguna sazón, ca siempre tenié ella en Él su coraçón. Versos que parecen adelantar los místicos amores y encendidos que proliferan en los siglos XIV y XV y llegan al XVIII ${ }^{37}$.

zando este apelativo el pasaje correspondiente, a manera de tic, como se ve por el reiterado encasillamiento en el verso $a$, y cuatro como "mártires" (versos 65a, 101a, 111a y 113b).

37 No parece haber un salto temporal entre estos versos de Berceo y los que escribirá santa Teresa tantos años después:

Ya toda me entregué y dí y de tal suerte he trocado que mi Amado es para mí y yo soy para mi Amado.

Esta poesía lírica parece fue escrita después del martes de Pascua del año 1571 (op. cit. p. 502). 
A pesar del desencanto de Oria, despertada, hay un final perfecto y temperado en este primer acto, como si "Don Cristo" y la monja emilianense se hubieran ya dado palabra de casamiento.

\section{SEGUNDA VISIÓN}

(Coplas 119 a 139)

Tercera noche ante del mártir Saturnino vínoli una gracia, mejor nunca li vino, más dulz e más sabrosa era que pan nin vino (119acd)

Comienza esta segunda parte del Poema con una fórmula que sirve de incipit y referente temporal, y es la de suplir las calendas por el santoral (119ab). El cómo, el cuándo y el dónde ocupan las tres primeras coplas $^{38}$.

Pasada la media noche "Vínoli una gracia" (c), fenómeno que parece producirse sin alteración externa, por flujo divino que, de modo natural, le mana del cuerpo y es consecuencia y producto de su estado de fatiga penitente: o cae en este sueño, o sucede como fruto de una prolongada vigilia, ante la incomodidad del lecho y la casilla donde yace emparedada.

Las coplas 121 y 122 presentan a tres vírgenes embajadoras (que a nosotros nos parecen otras distintas a Cecilia, Águeda y Eulalia, de lo contrario no sería necesaria su descripción, o quizá sean las mismas, ahora con otras funciones), vestidas de blanca pureza con paños de frisa y especificando solo dos de las prendas con que se adornan: toca y camisa ${ }^{39}$. Todas tres son iguales en edad, bondad, apariencia e indumentaria y se

38 Este uso se mantiene vigente en algunas comarcas del norte peninsular.

39 Del vestido que adornaba a estas vírgenes menciona Berceo solamente dos prendas: la toca y la camisa, que por algún motivo quiso destacar, aparte de su posible calidad o guarnición. En su tiempo era impensable imaginar una mujer honesta con solo estas dos piezas, fuera de un contexto de estricto oficio doméstico y reservado, que es el papel que tienen aquí estos personajes, amas y aposentadoras de Oria. La toca es un elemento de mujer que ha tomado estado (de casada o de monja), y estar destocadas solo tenía dos sentidos: el de virginidad y doncellez o el de prostitución, según en qué entorno. La camisa era considerada pieza de remudo o interior y en público siempre se completaba con otra prenda cimera. Berceo califica los paños que vestían las vírgenes como de fábrica de frisa, lana de calidad áspera y ordinaria y por ello impropia de estas embajadoras. Pensamos pues que por razones métricas o quizá por una atrevida traducción de la obra de Muño, dice Berceo frisa donde debiera decir paño de orfrés u orfresado, tejido, generalmente, con mezcla de oro y seda. 
comportan como ancilas que pulen y preparan la alcoba de su dueña, que va a recibir "lo bueno" ${ }^{40}$.

Se despliega a continuación una atropellada tramoya de mobiliario efímero que sirva con decoro a la visita y descensión de la Gloriosa, como cielo anticipado. Para que la casiella aparezca presentable se improvisa una cama de galas: "noble lechiga con adobos reales, non pobres ni mendiga" (123ab), "lecho muelle" (124b), "de ricos paños" (127b) con "cosas tan preciosas pora muy grandes omnes" (126d). Se está describiendo un dormitorio de aparato. ¿Qué sentido tiene este simpático trampantojo a la manera de palacio - entrometido en una atmósfera estrictamente conventual y ascética- que no le pertenecía a Oria, más propio de dueñas y abadesas con su espacio particular y bien delimitado en el monasterio? ¿Debía mostrar que la dignidad exterior reflejaba como un espejo la interior riqueza del alma? ¿O se trataba sin más de preparar un honroso recibimiento a Santa María?

Aparece este lecho impuesto como una arquitectura efímera de respeto, cuando lo objetivamente provechoso sería mantener el ambiente de pobreza y penitencia que hacen a la tocanegrada merecedora del cielo y de esta inesperada descensión. Sobre el criterio de virtud parece prevalecer el de una apariencia falseada de la realidad y el decoro. Priman los criterios terrenales del siglo y, entre estos, los de la sociedad noble y privilegiada, que subrayan la importancia del mobiliario y la indumentaria como escaparates de la estima, jobjetos tan ajenos a las miras de Oria! ${ }^{41}$

A la emparedada, tan hecha a lo malo, aquellas repentinas donosuras debieron resultarle difíciles de asimilar, y no extrañaría que tan disparatados planteamientos le hubieran parecido tentación del maligno — Liévate de la tierra, que es fría e dura, subi en esti lecho, yazrás más en mollura" (124 ab) - ante la insistencia al abandono de la penitencia y aceptación de lo placentero. Además, y dentro de su contexto, la situación creada nos parece inverosímil. En ambientes de disciplina (internados voluntarios y forzosos: conventos, cuarteles, cárceles...) se ha solido disfrazar la realidad cotidiana ante la visita, inesperada o no, de una autoridad. Por más que la imagen de Santa María o Nuestra Señora se presentara en esta época como reina —este tratamiento le da aquí también Berceo: «...la Reina, desto sei segura, si te falla en tierra, abrá de ti rencura" $(124 \mathrm{~cd}) —$, la merecida

40 En áreas de Salamanca y Extremadura se entiende por "dar lo bueno" recibir el sacramento de la Extremaunción y el Viático en el trance de la muerte. María viene a reconfortar la agonía de Oria y suple, en parte, ese sacramento. (Información recogida de Adela Novoa, hurdana que vivía en Miranda del Castañar).

${ }^{41}$ En este sentido trae Correas los refranes: "Como te ví te honré" o "Vestidos dan honor...n 
gracia de su visita no se debía más que a la mortificación y pobreza emparedada de Oria.

Como era de esperar, ella se resiste: "Lecho quiero yo áspero de sedas aguijosas, non merecen mis carnes yazer tanto viciosas". Utiliza con sabiduría Berceo dos términos contradictorios: sedas/aguijosas como recurso para expresar la lucha en que se debate Oria; con un aprendizaje ascético desde la infancia hasta lograr deleite con lo áspero, aborreciendo lo muelle ${ }^{42}$.

Ante la terquedad de Oria, estas vírgenes ancilas la fuerzan con una azotaina a estar presentable para la visita (pasaje candoroso y no exento de cierta vis cómica).

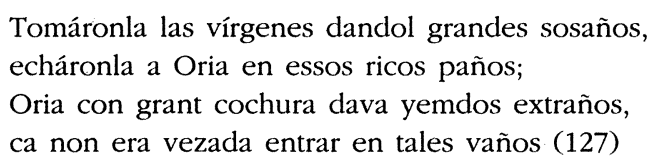

Queda la de Villavelayo preparada —en el lecho echada" (128a)— como para escenificar el Tránsito de la Virgen.

Tras la primera embajada de asistentas celestiales con carácter de intendencia doméstica, llega una segunda población y cohorte de vírgenes que bajan a honrar a la santa serrana (128d), portando grandes luces con que llenan de resplandor la ciella ${ }^{43}$.

Anticipa la copla 129 - Ende a poco rato vino Sancta María — la llegada de la Gloriosa, que se narra en los $n^{\text {os }} 132$ y 133 . Hubo arelumbror doblado en toda la confita" y "bienaventuranza" con la presencia de la que es "más fermosa de mucho que non es la aurora" (133b).

La cofradía de vírgenes, Oria y la Gloriosa entablan sus parlamentos. Las vírgenes, que actúan como muñidoras y maestras del ceremonial señalan los ademanes y compostura que debe guardar Oria: "Tú que yazes soñosa, levántate, recibi a la Virgo Gloriosa [...]; serás mal acordada si fazes otra cosa" (130). A renglón seguido le hacen las presentaciones (los títulos de María, bien asentados en la teología y en la mística: madre, hija y esposa, uno para cada persona de la Trinidad). En este precipitado cambio de situación y preparándose para lo que le anuncian como inme-

42 Es lugar común ser la seda sinónimo y prototipo de la suavidad.

43 Zurbarán en el lienzo de "La curación milagrosa del Beato Reginaldo de Orleans" (Sevilla, Parroquia de la Magdalena, c. 1626) compone una escena que nos recuerda mucho a esta "estoria" de Berceo. A La descensión de María entre un cielo de nubes que inunda la cama del enfermo, precede a la visita - como dos dueñas sevillanas en obra de caridad- de las santas Catalina y Magdalena, a ras de suelo, igual que las vírgenes que preparan la habitación de Oria. 


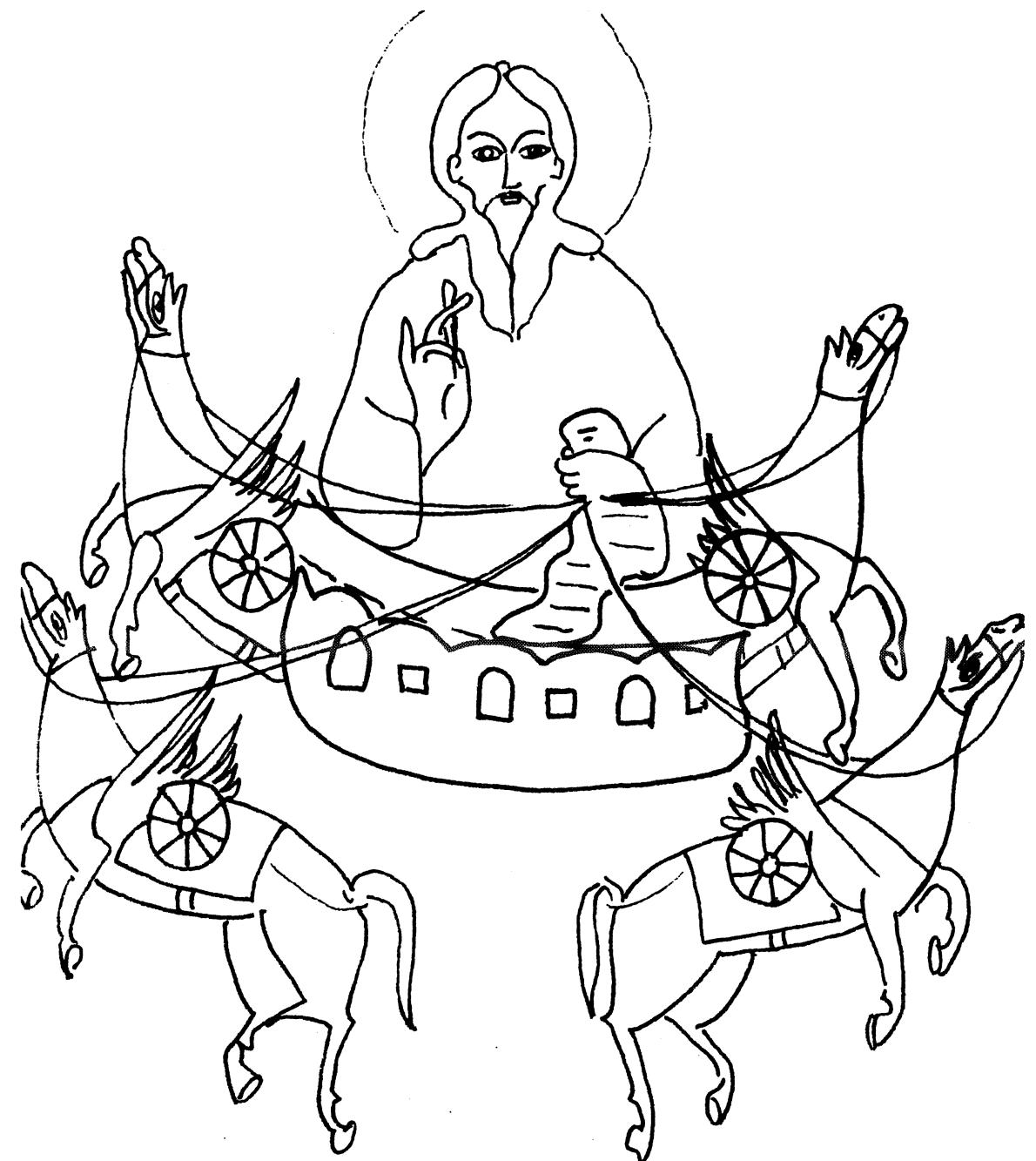

Fig. 8.-Ascensión del profeta Elías conduciendo una cuadriga de caballos alados. Mediados del S. XIX (Museo de Veliko, Tárnovo, Bulgaria). Dibujo de A. Cea.

diato - "ende a poco rato", "non lo puso por plazo nin sola una hora" (129a y 133c) — adopta Oria la suprema postura de humillación, conocida en su tiempo y por ella expresada, de "caer a piedes a la su majestat" $(131 \mathrm{~cd})^{44}$.

44 Ver en A. CEA GutiéRrez, El tesoro de las reliquias. Colección de la Abadía Cisterciense de Cañas (Logroño: Caja Rioja, 1999) las figuras correspondientes a la gestualidad de respeto y sometimiento entre ellas la de "caer a piedes"; pp. 81, 83, 90. 
Una vez descendida la Señora de los cielos y saltándose el protocolo, se "abaja" a abrazar a la serora.

Se establece, en las coplas 134 a 139 , un vis a vis coloquial de María y Oria, quien manifiesta su desconcierto ante el desajuste cognoscitivo que experimenta entre la iconografía de Nuestra Señora, a que está acostumbrada, y su presencia real, de cuya veracidad recela: "preguntoli si era ella Sancta María". "Non ayas nulla duda, dixol" (134bc). Insiste Oria en que le muestre una señal fiable: " si tu eres María [...] por seer bien certera algún signo querría, porque segura fuesse" (136).

Algunas de estas fórmulas de carácter jurídico, utilizadas en interrogatorios y apelaciones en casos de apariciones, parecen confirmar la duda general de la santa emparedada, a pesar de la prevención de las vírgenes, sobre si todo esto era obra y galardón de Dios o, por el contrario, tentación y mentira del diablo.

El tipo de diálogo que se establece entre María y Oria es el reglado - y como se ve aquí, muy antiguo- entre aparecido y vidente y entre éste y la autoridad eclesiástica, que pide una prueba evidente y milagro de esa hierofanía. Santa María responde y se somete a la costumbre, que no ve como desacato ni incredulidad: "Yo te daré un signo, señal buena provada, si la señal vidieses estonz serás pagada" (137cd), y añade: "Esto tú ten por signo, por certera señal: ante de pocos días enfermarás muy mal..." (138-139). El final apoteósico de este segundo acto vuelve a ser el tema de la silla, prenda suprema codiciada por Oria.

Esta descensión de la Virgen, que en principio amenazaba tanta etiqueta, se desarrolla al fin cargada de apelativos y gestos afectuosos. Quizá Oria no estuvo al inicio segura de hallarse en presencia de la Gloriosa, apeada de corona y cetro, avezados los ojos a su representación como reina y apareciendo en cambio aquí como madre y en ese tono le habla: "Madre, díxoli Oria" (136a). Santa María trata a la serrana de: "fijuela mía [...], fija [...], la mi lazrada" (134c, 135c, 137a).

Como advierte Isabel Uría ${ }^{45}$, la escena queda incompleta, debido a la falta del folio CIX, ya perdido cuando se paginó el códice en el siglo XVi; las 16 estrofas que lo ocupaban tendrían la despedida de la Virgen. Terminaría, pues, esta descensión de María y segunda visión de Oria con la misma tramoya ascensional y de apoteosis con que concluyen las comedias de santos.

45 Isabel URía, op. cit., nota 139, p. 532 de la ed. de 1992. La pérdida del folio CIX' afecta también al incipit de la tercera visión, donde se señalaría el día del santo en que la tuvo y su hora. 


\section{TerCera Visión. El MONTE OlivetTi COMO LOCUS AMOENUS}

Tal era la compaña, tal era el logar,

omne que ý morase nunca verié pesar (160 ab)

(Coplas 140-143). La escena transcurre en torno a la ciella de Oria. La visión del Monte de los Olivos está forzando la salida del alma de la soror, debilitado el cuerpo con síntomas de muerte ${ }^{46}$. A su alrededor, en velatorio anticipado, acuden conventuales ¿dúplices? y dolientes a recomendarle el alma.

Podemos entresacar los siguientes personajes: Un primer grupo, más numeroso, probablemente de monjas y monjes: "sedié un grant convento de fuera de la ciella, /rezando su salterio, cascuno en su siella" (140).

En segundo lugar, "Otras buenas mugeres que cerca li sedién, vedién que murmurava, mas no la entendién" (151ab). Personajes en la línea evangélica que se perfilan como "Santas mujeres" o "piadosas mujeres" con un papel en los pasajes de la Pasión de Cristo un tanto desdibujado y secundario como comparsa, y cuya actividad definiríamos con gestos de compasión, actuación dolorosa y agrupada. Funcionan como telón de fondo del personaje principal, coro de Parcas y, un tanto, de curioso comadreo.

En medio de estas sorores (149b), Amuña, madre de Oria, con actuación convulsa se esfuerza por devolverla del viaje-visión a la vida: "comenzó de traerla, ovo a despertar" (147d).

Por último, pone Berceo en escena a Muño (el autor de la fuente latina del Poema) y personaje de confianza de Amuña: "La madre de la dueña fizo a mí clamar, fízome en la casa de la fija entrar, yo que la afincasse, si podiese fablar, ca querié dezir algo, non la podrién entrar" (152). El término "casa" parece aquí mucho más que "ciella" o "casiella": el propio cuerpo de Oria y templo de su alma del que, veían, se escapaba.

Muño, cuyo cometido ahora es la introspección espiritual, juega un papel de confesor-ensalmador; el que puede lograr el milagro de volverla del viaje y hacerle hablar. Como entre discípula y maestro o amo espiritual, Oria y Muño inician un parlamento de desiderium gloriae (coplas 153 a 162). Tiene así ocasión la santa de redondear la historia de vida de su visión, la partida al cielo desde el Monte Oliveti (157-160); pasaje que

46 Recordemos el caso prototipo de Santa Teresa en las experiencias místicas y éxtasis, testimonio que cifra en los versos: ... "y tan alta vida espero, que muero porque no mueron; estado tan paralelo al que experimenta Oria. (Efrén de la Madre de Dios y Otger STEGGINK, op. cit., p. 502). 


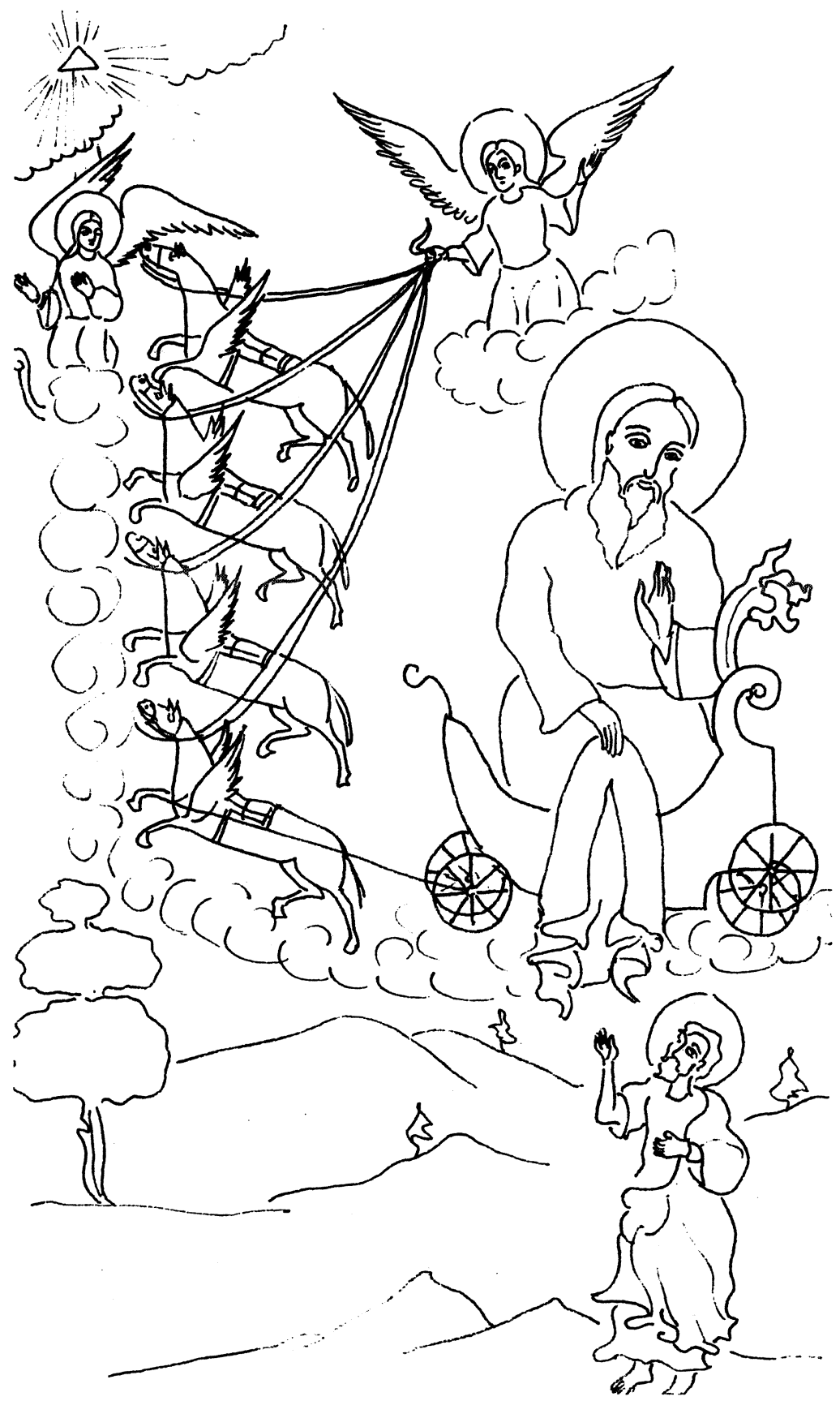

Fig. 9.-Ascensión de Elías que deja caer su manto para Eliseo a quien bendice. Lleva las riendas un ángel mientras otro le guía hasta el Padre Eterno. S. XIX (Museo de Veliko, Tárnovo, Bulgaria). Dibujo de A. Cea. 
ya había llenado las coplas 142 a 146 y que constituye el argumento principal de este acto ${ }^{47}$.

A Oria le vino la visión en un momento en que se había quedado adormecida (142ab): "Traspúsose un poco ca era quebrantada". Cuenta y repite cómo "fue a Mont Oliveti en visión levada", "Fui a Mont Oliveti en visión levada" (157c). Aquí no se dice "tener visión" sino "ir en visión"; la santa viajó y lo hizo a un espacio que se plantea como locus amoenus. La fórmula regular y preceptiva de esta experiencia es "vido" (142c, 143a, 144a y 146a); la expresión encomiástica: "nunca lo ovo visto" (146c), y la comparativa: "otras tales vidiera en algunas sazones" (145d). Nunca tiene lugar el viaje en tiempo de vigilia sino de sueño, adormecimiento, fatiga, quebranto y medianoche.

47 Vid. en A. CEA, op. cit., pp. 31, acerca del Monte de los Olivos como aeropuerto para el cielo. Aunque en la iconografía cristiana - al menos desde el arte bizantino al románico inclusive- la pareja arquetipo inicial fue la mano divina del Padre ayudando al Hijo, que asciende a pie desde el Monte, de hecho, el Cancionero y el Romancero nos han transmitido en su lugar la figura de María ayudando en ese trance a sus hijos y devotos, como se refleja en el ejemplo siguiente:

Postrémonos de rodillas delante de esta Señora, que ella nos dará la mano para subir a la Gloria.

(Estrofa final que se canta en la procesión del Encuentro, la mañana de Pascua de Resurrección, en Miranda del Castañar). A partir del siglo xv el auxilio de María se concreta bajo la advocación de $N^{\mathrm{a}} S^{\underline{a}}$ de la Misericordia, protegiendo -hasta la alcahuetería - a las almas pecadoras, devotas suyas, de la ira divina y jugando con el doble papel mediador de su doble maternidad, divina y humana. Da la mano o una prenda, entre nubes, a las almas que suben al cielo; puede hacerlo como Virgen del Carmen, librándolas de las llamas del Purgatorio:

$$
\begin{aligned}
& \text { La Virgen con nueve coros, } \\
& \text { cuando dan las ocho, llega } \\
& \text { y saca del Purgatorio } \\
& \text { a la que purgó sus penas. }
\end{aligned}
$$

(Versos 33-36 de Las horas de las Ánimas, versión albercana de Dolores Mancebo, de 98 años, recogida en junio de 1980).

Por extensión y en la escala mediática de los santos intercesores, destacamos la popular presencia de Santa Bárbara, abogada contra rayos y centellas. La oración con que se acude a ella incluye en su final la petición, también, de la Gloria celestial.

$$
\begin{aligned}
& \text {... Santa Bárbara bendita } \\
& \text { ruega a Cristo nuestro bien, } \\
& \text { que nos de salud y gracia } \\
& \text { y después la Gloria. Amén. }
\end{aligned}
$$

(versos 20 y 21 de la versión romanceada de Miranda del Castañar, recitada por Adela Novoa, de 79 años; octubre de 1973). 
El Monte Oliveti (143) se describe como una pintura de país, enmarcada por una hermosa llanura cubierta de gran espesura de olivos que caían de la carga de olivas, sobre las que Berceo no puede reprimir una atinada consideración, propia de un buen cillero: "podré bevir so ellos omne a grant folgura" (d). La descripción anterior se reitera, enriquecida, en las coplas 157-160: abundancia de árboles —no especificados ahora como olivos- y frutos cuyo olor sanaba a los enfermos.

Oria define el estado de gozo que experimentó con la visión del Monte como que "sedié en grant gloria en sabroso logar" (148c). Prima en esa descripción una cualidad gustativa, de banquete, sensación que vuelve a repetir en la copla siguiente: "ca sedié en grant gloria, entre buenos señores". Con esta reiteración — «edié, - parece subrayar la posición sedente, de poder y hedonismo en la gloria, más el deseo y la satisfacción de compartirla entre unos personajes nobles y de élite. La obsesión de hacer eterna esta ventura le lleva a balbucir entre dientes: "Monte Oliveti, Monte Oliveti» (150b). Este es su eti eti hindú (el "esto sím), reposando en este locus amoenus y "logar bueno" (158a).

De los personajes con que se encuentra dice que son "grandes gentes de personas honradas, ca entre tales omnes era yo arribada" (155c), como si se tratara de un testimonio de probanza de sangre y linaje; cualidades que se reconocen y manifiestan por su indumentaria: "bien vestidos y calzados". Oria reconoce entre ellos a un paisano suyo: "Sancho li dixeron el barón massellano" (146b). Volvemos a la identificación de personajes locales, o vecinos, ahora celestiales: "pero la serranilla conosció al serrano" (146d) ${ }^{48}$. La calidad con que recibieron a Oria fue de cantos de laudes bien acordados y al unísono. Quien allí morase no tendría nunca pesar (160b).

No solo desea volver a ese estado visionario sino arrastrar a los suyos, concretamente a Muño, su amo honrado ${ }^{49}$.

48 Incide Berceo aquí en el aspecto de "paisanaje", tema ya desarrollado en la Vida de Santo Domingo de Silos (copla 675b). Ver el comentario en A. CEA, ibid., p. 91. Debió de reconocer al venerable anciano Sancho por cualquiera de las características que a continuación enumeramos: el acento, la "pinta", el traje, o porque había oído contar de niña sus historias en casa. La expresión "nunca lo ovo visto" queda reforzada con la siguiente: "nil tanso de la mano" (146c); argumento a pectore de oralidad transmitida desde la infancia por un informante longevo —un omne anciano" (146a) que acompaña su recitación con la fuerza gestual y afectiva de las manos, a las que se cogía la niña Oria.

49 Las coplas 143 y 158 parecen proceder directamente de los Dialogui de San Gregorio Magno en el pasaje de la visión del soldado Esteban: "Transacto autem ponte, amoena erant prata atque virentia odoriferis herbarum floribus exornata, in quibus albatorum hominum conventicula esse videbantur. Tantusque in eodem loco odor suavitatis inerat, ut ipsa suavitatis flagrantia illic deambulantes habitantesque satiaret. 
Queremos señalar la importancia del pasaje acogido a las coplas 144146, seguramente uno de los testimonios primeros en lengua castellana del motivo folclórico conocido hasta hoy (y nombrado ya así en Berceo) como "Santa Compaña". Recoge con claridad las características de estos personajes cuando dice:

Vido por essa sombra muchas gentes venir.

[...] Eran estas compañas de preciosos barones,

todos bestidos eran de blancos ciclatones (144a y 145ab).

En este caso, la hueste que apareció en Suso fue positiva y de gloria; vinieron a recibir de grado el alma de Oria, no a arrebatarla por fuerza $(144 \mathrm{~b})^{50}$. Como en algún pasaje anterior y con la excusa, ahora, de la difícil clasificación de la Hueste, vuelven a definirse los ángeles, como sexuados varones (145abc).

Oria, con el gesto de abrir los ojos, viene a expresar la vuelta a la realidad y la cordura terrenal y el abandono, al menos temporal, del viaje a ese cielo (154b), y el recelo de no recuperarlo jamás: "que nunca allá podrié tornar" (148d), "Ay mezquina, estava en grant gloria" (154c). Parece natural, por ello, la inquina hacia sus despertadoras - la madre y las sorores- (149ab) y el lamento de Oria dirigido a esa comunidad de plañideras que tiran de ella para que se mantenga viva. Esa visión, continuada, le hubiera arrebatado la vida y devuelto la felicidad: "si un poquiello me oviesen dexada, grant amor me fizieran, sería terminada" (155ab).

Para LLOMPART “esta línea iniciada por Gregorio Magno [...] se inserta en el Alto Medioevo". Ver "Aspectos populares del purgatorio Medieval" en Religiosidad Popular. Folklore de Europa (Palma de Mallorca, 1982), p. 259. Citando a R. Miquel Planas, Llegendes de l'altra vida (Barcelona: Biblioteca Catalana, 1914) pp. 71-72, trae Llompart la trecentista Visió de Tundal: "Veheren I camps molt bell e ben olent e ben flayrant et ple de flors e molt resplandent [...] e molt deleitós en lo qual havia moltes animes d'omnes e de fembres q se alegraven [...]. En aquest loch habitavem los bons, mas no fort bons.... [Es obra contemporánea del Poema de Santa Oria].

50 "Santa Compaña" es la denominación más extendida de este fenómeno legendario, especialmente en Galicia y Asturias, donde se conoce como "Güéstiga" o "Güeste", creencia que ha circulado en esa geografía hasta hoy. Se describe como un número indeterminado de almas en pena, aún sin gloria, que se muestran vagando de noche, vestidas de blanco, a veces alumbrándose con cirios, a manera de procesión de penitentes y acechan con la muerte o la presagian en los cruces de los caminos a quienes, a esas horas de la noche, transitan en solitario. Es hueste que reina en las sombras, en cuya boca se pone como salmodia reiterada la cantinela: "Andar de día, que la noche es mía" (así lo aprendíamos de niños en Asturias). Este cortejo debe ser evitado pero, ante su presencia imprevista, se utiliza como conjuro la señal de la cruz formada con el pulgar y el índice de la mano derecha o haciendo la higa. 
Sopesa Berceo el buen trabajo de su Poema, los resultados objetivos de esta historia y la satisfacción por los mejores datos que cebaron la fuente de la que bebe: Las vivencias de Oria, la visión final de su madre - Amuña- y la de su marido García, así como las que Muño recoge de madre e hija en los versos siguientes. "Recontógelo todo [Amuña] a Muño [...], él decorolo todo como bien entendido":

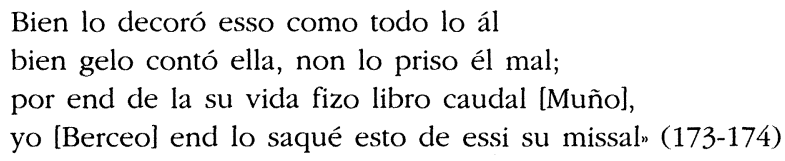

Muño, su amo espiritual, se propone completar fielmente esta hagiografía y proceso visionario de labios de la propia santa.

Apasionante pasaje donde, como en pocos ejemplos, se analizan la tradición-transmisión-traslación de las Vitae sin que falte ni sobre nada de verdad. Berceo, luego "lo saca" y transcribe, pasado un tiempo, al lenguaje inteligible de su época.

"Oria abri los ojos, oirás un buen mandado" (153b). Se funden y mezclan aquí las funciones de los sentidos —en la interpelación de su madre y de las seroras, recaderas de la visita del maestro espiritual- porque los ojos en vigilia son señal de captación de la realidad y de la sabiduría, incluso en la oscuridad de la noche, si se presentan como símbolo, perpetuamente abiertos (así lo emblematiza la lechuza).

La figura de Muño representa al colector que hace fiel seguimiento de la información de Oria y de su estoria — desde la cama a la tumba-, de la que quiere ahora desentrañar algunos pasajes oscuros: "Amiga, dixo [Muño] esto fáznoslo entender, bien no lo entendemos, queriémoslo saber; esto que te rogamos tú déveslo fazer " $(156 \mathrm{bcd})$. Está, además, la narración directa que sale de boca de la santa y la que, calladamente, hubo de percibir día a día. Como su maestro, recibe la añadida información "completativa" de lo que Amuña guardaba en su corazón. Oria en su agonía tranquiliza a Muño sobre la objetividad de los hechos y detalles biográficos: "Amigo", dixo ella, "non te mintré en nada" (157a).

\section{MUERTE DE ORIA}

(Coplas 164 a 189). Se inicia el pasaje con la presentación de las coordenadas espacio-temporales de su agonía y muerte: 
El mes era de março, la segunda semana, fiesta de San Gregorio [...],

hora quando los omnes fazen meridiana $(164 \mathrm{abc})^{51}$

Don Muño y el cillero Don Gómez aconsejan acostarse a Amuña y quedan mientras ellos velando el trance de Oria como recomendadores de su alma, "si quisiere pasar" (d), o sea, si en el ínterin muriese.

\section{Visión de Amuña}

Amuña en sueño presagioso y bien interpretado "vido visión" (167b). Se le presentó su marido Don García que venía a buscar desde el otro mundo a su hija Oria: "entendió bien que era por su fija venido" (168c). Se hacía acompañar por tres personajes, también de santa vida, de increíble blancura, todos de la misma edad y presencia (la edad perfecta de 33 años a la que, según la creencia, resucitaban los cuerpos, la edad de Cristo), sin hablar ni hacer gestos; todos igualados por la imagen de la muerte. Llegó la hora de cumplir lo que, en un pasaje anterior, anunciaba aquella Santa Compaña.

En ese parlamento familiar entre esposos, él le anuncia que Oria vive su último día terrenal: "de las sus jornadas ésta es la postremera" (170171). De nuevo se dibuja el paso por este mundo con el símil del destierro por el que se camina en jornadas. Ante la evidencia de la hora certera, Amuña hace partícipe a su esposo de la importancia de completar la biografía de su hija.

Hay un nuevo planteamiento - desgraciadamente no podemos deslindar si como aportación original de Berceo o aparecía ya en la obra de Muño- en el Poema de Oria acerca de la transmisión oral y escrita. Muño y Amuña figuran como albaceas de la estoria de la santa emparedada, discurso que estructuramos en los siguientes apartados:

- Muño se define como biógrafo y testigo de excepción, cuya Vita pondrá con fidelidad por escrito: "de la su vida fizo libro caudal" (174c).

- Berceo, a su vez, será transcriptor que ponga en romance la estoria, que entiendan los lectores (o narradores) de su tiempo y los venideros: "Yo end lo saqué de essi su missal" (174d).

51 Meridiana: lo que en los Siglos de Oro se conoce como "hacer mediodía". Tiempo central — que divide en dos la jornada - aprovechado para la comida y un descanso, especialmente cuando se va de camino; voz muy usada en boca de arrieros, caminantes y trajineros. Quizá tenga aquí, además, un sentido figurado, el del bomo viator que camina hacia la vida eterna. 
- Amuña, en su papel de intermediaria y como madre, conjura a Oria a contar la última experiencia celestial antes de que le abandonen los sentidos: "Si visión vidiestes o alguna historia, dezítmelo de mientre avedes la memorian $(175 \mathrm{~cd})$. Se subraya aquí la memoria como vehículo de la tradición oral.

- Oria queda dolida, en su vivencia de informante, de que su propia madre, aquí como colectora, sacrifique la agonía de su hija a la egoísta necesidad de procurar información de su vida. Queja que expresa la santa en los desgarrados versos siguientes, en impresionante testimonio de transmisión oral in extremis:

$$
\begin{aligned}
& \text { más me pesa la lengua que un pesado canto. } \\
& \text { Queredes que vos fable, yo non puedo fablar, } \\
& \text { veedes que non puedo la palabra formar, } \\
& \text { ante de la mi hora me puedo enfogar (176d, 177abc) }
\end{aligned}
$$

- Aún resistiéndose, porque no es hora de contar sino de lucha (178), supedita heroicamente Oria la propia agonía a la narración detallada de su vida en aquel trance: "aún assaz tenía cosas que vos dezir".

Las coplas 179-180 son ejemplo espléndido de la confiada y serena gestualidad, propia del vir iustus cuando entrega su alma a Dios: haciendo la señal de la cruz, alzando las manos al cielo, dejándolas luego juntas en postura orante y cerrando ojos y boca ${ }^{52}$.

De "essi passamiento" fueron presentes y testigos el buen abad Don Pedro, máxima autoridad de la "confita" y el grupo de monjes y ermitaños del conventus, que define ese espacio ascético de Suso como una sociedad dúplice y mixta, en comunidad de monasterio y eremitorios (181). El salto del alma se dio al oscurecer: "boca de noche era" (179b).

\section{EL ¿PURGATORIO? DE ORIA COMO EPÍlOGO}

A nuestro entender, el epílogo comienza en la copla 187 cuando Berceo (¿o quizá Muño?), sintiendo tener que dejar detalles de esta estoria en el

52 Esa gestualidad, estereotipada, en la manera cómo los santos expiran aparece ya en la Vida de San Millán de la Cogolla, enriquecida, además, con los signos de su rango de abad - alzar la mano diestra para bendecir a la comunidad y petición de oraciones- (copla 300). En esa traza de gestos fue ayudado por el mismísimo Santiago el Mayor, que descendió a recomponer ese "complimiento": "tendió ambas sus palmas, juntólas muy a tiento; cerró ambos sos ojos" (301abc). La misma fórmula se describe en la Vida de Santo Domingo de Silos (copla 521): "Fo cerrando los ojos [...], apretó bien sus labros [...], alçó ambas las manos a Dios nuestro Señor, rendió a Él la alma...". 
tintero exclama: "aun fincan cosiellas que voz e de dezir" (b), queriendo ponerse a salvo de críticas posteriores: "que non aya ninguno por qué me escarnir" (d).

Las coplas 188-189 describen los sufrimientos de Amuña por la ausencia de su hija y la incertidumbre de su paradero en el viaje post mortem, deseando - al menos- tenerla presente en sueños: "sólo que la podiese soñar una vegada" (188c). Dios lee en su corazón y la conforta con "una grant visión" (189b); sueño que se desarrolla en la copla 192. De ese texto se infiere que Amuña no percibió a Oria como alma glorificada sino purgante. Para ello recurre al discurso de los aparecidos familiares que se presentan a pedir oraciones para salir de ese trance.

El orden de esta visión se inicia con un saludo de paxtecum y la angustiada y consabida pregunta a la difunta: "quiero que me digades quál es vuestra venida o si sodes en pena o sodes end salida" (cd). Ignora si

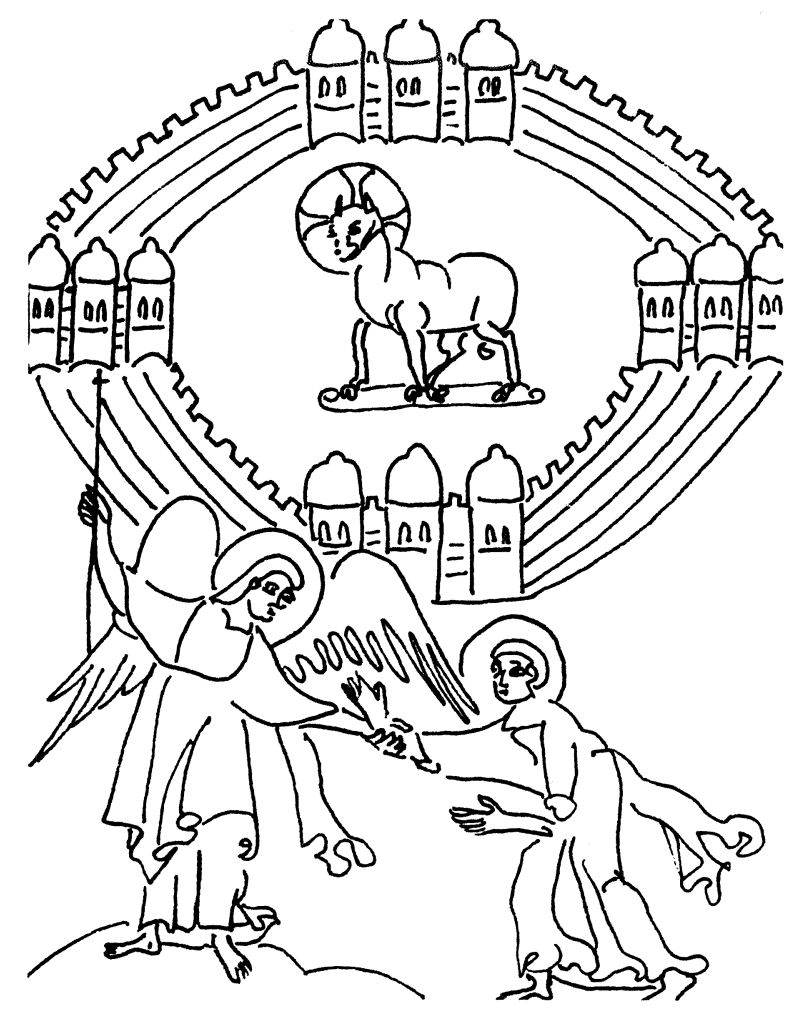

FIG. 10.-Un ángel, desde el monte de los Olivos, ayuda con su mano izquierda a un bienaventurado y porta en la otra un "blago" o cayado para la subida a la Jerusalén Celestial, en cuyo centro reina el Agnusdei. Apocalipsis de Bamberg iluminado por Reichenan para Enrique II. Siglo XI. (Dibujo de A. Cea). 
su alma anda aún rondando la celda, cercana al sitio de su muerte. Quizá Amuña, acosada por la superstición y creencia recibida, llegó a temer que el espacio cerrado de la ciella-emparedamiento, obstaculizaba el vuelo celestial de Oria ${ }^{53}$. En principio y por las explicaciones de la santa, parece que su alma vagaba al no haber recibido en la agonía el corpus domini: "yo essi quiero, madre, rescibir e tomar, e tener mi carrera, allá quiero andar" (194c) ${ }^{54}$. El día, tan señalado, de Quinquagésima o Pascua de Espíritu Santo, era uno de los tres que en tiempos de Oria se recibía la comunión preceptivamente.

Este discurso de la última venida de Oria desde el más allá para comulgar nos lleva a la pregunta: ¿Es más perfecta, placentera e íntima para el alma la comunión que la propia visión beatífica en el cielo y el logro allí del unum cum Deo, o in Deo?

53 Luis de Hoyos SÁINZ, "Folklore español del culto a los muertos", RDTP, I (194445), esp. p. 37, dice: "... existen costumbres generales a toda Europa [...], en lo que atañe a los familiares y a la casa, la de abrir puertas y ventanas para que salga el alma del expiranten. Probablemente recogió estos datos de las papeletas de la Encuesta de 1901 sobre costumbres de nacimiento, matrimonio y muerte que por entonces se conservaba aún en el Ateneo madrileño. Ignacio FERNÁNDEZ DE MATA en De la vida, del amor y la muerte: Burgos y su provincia en la Encuesta del Ateneo de Madrid (Burgos, 1997), p. 137 y bajo el epígrafe "Comprobación de la muerte", en relación a la localidad de Briviesca, dice: "Lo general es que sea el sacerdote el encargado de anunciar la defunción, rezando un responso, abriendo la ventana del balcón...”. En la nota 155 aclara este autor: "se abre la ventana para que salga el alma". Según nos informa Carmen Ortiz García, a quien agradecemos el dato, esta costumbre se mantenía aún en 1998 en la comarca alcarreña de Tendilla, donde una tía abuela suya, una vez amortajado el cadáver del marido, mandó a una sobrina: “Carmen, abre la ventana".. "¿Por qué, tía, si hace mucho frío?", "Abre, abre para que salga el alma"; ventana que mantuvo de par en par toda la noche.

54 Se plantea aquí el tema de la communio post mortem, que parece contrario a la teología de los méritos propios, dentro de la Iglesia Militante en vida, y al valor impetratorio de los fieles, que pueden aliviar a quienes, en la Iglesia Purgante, no tienen capacidad de merecer, pero sí de recibir méritos ajenos, gracias a la llamada teoría de los vasos comunicantes, dentro de lo que se conoce como Cuerpo místico: oraciones y misas para salir del Purgatorio y pasar a la Iglesia Triunfante en el cielo. No podía Oria, de muerta, acumular los dones que se le habrían otorgado de haber recibido, en su agonía, el Viático. La copla 195 abunda en el tema de la comunión en una de las tres fechas litúrgicas anuales que, en tiempos de Oria, se recibía como práctica obligada (vid. nota 194 de la ed. de B. Dutton, p. 548).

Para Ruiz Domínguez, El mundo espiritual de Gonzalo de Berceo, I (tesis doctoral. Universidad de Sevilla, 1994), son sujetos del sacramento eucarístico todos aquellos que están en peligro de muerte tras confesar (p. 251). Agradezco esta información al doctor Soto Rábanos. En este pasaje ve el autor "una transgresión típica de la mentalidad medieval, mundo celestial-mundo terrenal [...]. Simplemente el deseo [de la Iglesia] de potenciar este sacramento" (p. 253). 
La expresión "carrera de salvación" como fórmula en algunas oraciones domésticas tradicionales que se han conservado hasta hoy, viene a significar el camino sin obstáculos pero trabajoso hacia la Gloria Eterna del alma, arriera por una vida santa y camino acertado, sobre todo cuando llega la muerte.

Insiste Amuña en el trance del "passamiento" (197b) y tempus errático de Oria, esperando a las puertas del cielo (tema que se presenta ya en la iconografía de la época), o, si por el contrario, tuvo un acomodo inmediato: "Si vos dieron luego en el Cielo logar, o voz fizieron ante a la puerta amusar". "QQuién voz fizo compaña mientre fuera oviestes?" (197cd y 199b). Pormenoriza Amuña todos los passos para el ingreso de su hija, queriendo matar sus congojosas dudas, las de todo cristiano ante la incógnita de las postrimerías.

Las respuestas de Oria parecen establecer dos posiciones experienciales que casan mal, la de la peregrinación errática y la de la entrada inmediata, aunque parece que estuvo un día en espera: "non entré en palacio, non se por qual manera; otro día mañana abrióme la portera" (190bc). Por último, el final feliz y recibimiento general de las jerarquías: "rescibiéronme, madre, todos por compañera" 55 . En el parlamento de Oria con su madre, quiere sosegarla con respuestas positivas acerca de esos momentos de espera, nunca desamparada por las tres guionas y Santa María y embebida "en tal delicia" (199 c): "La Virgo Gloriosa [cumpliendo su promesa] en el mi passamiento de mí non se partión (200ac). Presenta aquí

55 San Pedro con su oficio de clavero -iconografía que nos data Berceo post quem (c. 1256) - queda aquí desplazado por la figura de una portera, como si se tratara de un monasterio de monjas, aunque sí aparece con este cargo en Los Milagros...: "Rendieron a Dios gracias [...], e al sancto apóstolo, clavero celestial" (179ab; 7, "El monje y San Pedro"). Las llaves como el atributo prototipo de sus imágenes aparecen en la siguiente estrofa:

\section{San Pedro Galán diligente... \\ fue apóstol y marinero, \\ tiene las claves del cielo.}

(Danza para la Velada del Corpus Christi en Llanes, recogida a Benita Mijares Carriles de 87 años, en 1960). Sobre el tema de la espera y purgatorio $c f r$. Gabriel LlOMPART, "Aspectos populares del Purgatorio Medieval", RDTP, XXVI, 3. ${ }^{\circ}$ (1970), p. 256: "Tras el puente, el ascenso a la gloria es mera cuestión de tiempo [...]. Se puede preguntar entonces, por el sentido de las pruebas del viaje: todas son purgación de pecados, porque todos los estadios - salvo el pozo del fuego, que es la bocana del infiernotiene finalidad expiatoria". No hubo tormento material en el caso de Oria y estuvo muy bien acompañada, pues define esa espera como "sovi en tal delicio" (199d). La pena aquí era no gozar aún de la faz de Dios. Para Llompart el tema de la peregrinatio y el paso del puente para la Gloria tienen una fuente directa en los Diálogos de San Gregorio Magno (Dialogi; 1-4, c 36). 
Berceo a la Gloriosa como mediadora y puerta del cielo, en una prefiguración del tema de $N^{\underline{a}} S^{\underline{a}}$ de la Misericordia y, la posterior, del Carmen.

\section{Ubicación general entre las jerarquias}

A la interesada pregunta de Amuña (papel que recuerda el del evangélico pasaje de la Madre de los Zebedeos) sobre su situación, premiada y jerárquica en el cielo: "en qual compaña sodes, fazétmelo entrar" (201b), responde Oria: "Entre los innocentes so, madre, heredada, los que puso Erodes por Christo a espada" (202ab). Esta herencia de gloria — para los considerados por la Iglesia con el rango de Inocentes, muertos sin el Bautismo ${ }^{56}$ - debería corresponder al Limbo, lugar sin pena ni gloria, de la inocencia y por tanto poca para una monja que pasó su vida emparedada. Pero estos Inocentes, los de Herodes, son en realidad tenidos aquí por protomártires, adelantándose al propio San Esteban. No queda bien definido en el Poema el escalafón de Oria, que no parece se sitúe con las vírgenes (en las distintas visiones del cielo ocupaban la tercera escala o jerarquía) y entonces se distanciaría, finalmente, de sus tres guionas, hasta aquí inseparables. De la alusión al pasaje de la Matanza de Herodes parece desprenderse su ubicación con los Inocentes, en lugar destacado de la quinta jerarquía, o de los Santos Mártires.

Esta espléndida, sagrada representación literaria concluye con el final de la visión que, parece, solo tuvo lugar con los ojos del corazón y con el llanto, ahora de consuelo, de Amuña: "fuyoli a la madre de los ojos corales, despertó luego ella, mojó los lagrimales" (203 cd).

Acelera Berceo el finis (coplas 203-205) dando carpetazo al Poema en un tono de gracioso y juglar - prisas que ya hizo notar en la copla 163 , quizá innecesarias- y omitiendo otras muchas visiones que sí se encontrarían en la fuente original de Muño. No falta como recurso la captatio benevolentiae, aquí a lo divino: "que vea la su gloria en el Reyno Mayor" (d).

56 Según Santo Tomás de Aquino, en su concepción del cielo (ver este capítulo en MC DANNEEL-LANG, op. cit.), no es igual la contemplación de los bienaventurados, sino proporcionada según los grados de mérito. La escala inferior correspondería a la de los niños sin bautismo (limbo), que equivale a una felicidad natural como animal, no sobrenatural, si bien todos los estadios del cielo son perfectos según su medida. 
Los nombres de Dios en el Poema de Santa Oria

- Señor (nuestro, natural, señor de señores, señor y padre) $=5$ veces (22b, 106a, 116a, 205c).

- Criador (que nos quiso criar) $=4$ veces $(1 \mathrm{a}, 76 \mathrm{~d}, 108 \mathrm{a}, 178 \mathrm{c}$ ).

- Rey (de gloria, de majestad, de reyes, espiritual) = 4 veces $(69 \mathrm{a}$, 102b, 116a, 180b).

- Padre (y señor, el buen padre sancto, que nos quiso criar) $=3$ veces (1a, 106a, 176b).

- Esposo (nuestro) = 1 vez (71c).

- Papa (Jesu Christo fue papa) = 1 vez (90c).

- Dios del cielo $=1$ vez (103c).

- Cristo Salvador $=1 \mathrm{vez}(1 \mathrm{~b})$.

- Espiritu Santo, luz confortadora $=1 \mathrm{vez}$ (1c).

- Corpus Domini = 1 vez (194b).

\section{Apelativos con que se nombra a Oria}

- Fija o fijuela $=28$ veces (querida, amada, benedicta, mía. Aparece en boca de sus padres, de las tres vírgenes guionas, de Dios, de la Virgen) ( 40a, 53d, 57a, 109c, 110c, 123d, 134c, 135d, 152b, 168c, 170d, 171c, 175a, 175b, 185a, 188a, 189c, 191d, 192d, 193a, 196a, 196b, 197a, 198a, 199a, 201a, 201c).

- Serrana y Serranilla $=4$ veces $($ ) (54d, 62a, 65a, 146d).

- Niña $=2$ (48a).

- Doncella $=1$ (48a).

- Virgen $=2(11 \mathrm{a}$-virgen preciosa-, 51a).

- Sancta $=5$ (28d, "plena de sanctidat"; 99a -en boca de Berceo-; 182a, "Sancto cuerpo", ya muerta; 188a, "Sancta emparedada"; 183b, "de tan grant sanctidat")

- Sancta Virgen $=2(2 \mathrm{~b}, 5 \mathrm{~b})$.

- Vaso de electión y vaso de caridat $=2$ (5b y $25 \mathrm{a})$.

- Templo de paciencia y bumildat $=1$ (25b).

- Luz y confuerto $=1$ (25d).

- Piedra preciosa y oro $=1(4 \mathrm{~cd})$.

- Amiga = 3 (97b, 123c — "buena amiga de Dios", en el sentido de dilecta, querida, que tiene en el Cantar de los Cantares-; 156b -en boca de Muño-).

- Novia $=1$ (67c — del Esposo divino; se pone en boca de Berceo- $)$. 
- Compañera $=2$ (35d; 78a -así la llaman las tres vírgenes guionas-).

- Hermana $=2$ (36a; 65b -las dos veces lo utilizan las tres vírgenes guionas-).

- Serora $=1$ (133d).

- Freira $=7$ (60b, 66b, 70b, 74a, 96a, 128a, 131a).

- Dueña $=7$ (45b, 49a, 152a, 163c, 164d, 165a, 183b).

- Tocanegrada $=1$ (20a).

- La que siempre bistié lana $=1$ (164d).

- Emparedada $=9$ (20b, 21b, 24b, 26a —emparedación-; 34 paredes cerrada,$- 77 \mathrm{c} —$ entrada entre paredes»-; 128d, 137b, 188a — -sancta emparedada-).

- Reclusa $=9$ (25a, 38a, 45b, 52a, 58a, 64a, 167d, 180c 一reclusa leal»).

- Enferma $=2$ (141a, 148a).

- Lazrada $=1$ (137a —la mi lazrada"; en boca de la Gloriosa).

- Benedicta $=1$ (203b: -en boca de Berceo, como apelativo e invocación final).

Nombres que recibe el espacio en que babita la emparedada

- Logar o su logar = 3 (104a, 162c, 166a —en sentido más general: todo el monasterio).

- Confita $=1(132 \mathrm{c})$.

- Casa $=2$ (147c, 152b).

- Casiella $=2$ (110d, 140a).

- - Ciella $=2$ (128b, 140b).

- Posada $=1$ (150c).

- Lecho $=4$ (124b, 125b, 126a, 166c).

- Cameña $=1$ (120d).

Cielos-cielo-gloria

- Cielos $=12$ veces (6d, 26d, 36c, 39b, 39d, 41b, 44b, 53a, 107a, 109b, 133a, 196b).

- Cielo $=6$ veces (27b, 33a, 49c, 54a, 144d, 197c).

- Gloria $=3$ veces $(57 \mathrm{~d}, 175 \mathrm{~b}, 205 \mathrm{~d})$.

- Estar en $=1(57 \mathrm{~d})$.

- Sobre $=1$ (39b, 44b).

- Dar lugar en = 1 (197c).

- Altos $=2$ (107a 109b). 
- Abiertos $=1$ (54a).

- Ver o mostrar $=4$ (6d, 27b, 49c, 205d)

- Subir o pujar = 7 (36c, 39d, 41b, 53a, 109b, 144d, 196b).

- Entrar $=1$ (54a).

- Horadar $=1(26 \mathrm{~d})$.

- Coronar $=1$ (33a).

\section{Expresiones de percepción en las visiones de Santa Oria}

- vido en los Cielos una grant visión (5d).

- li mostró en el Cielo tan grandes visiones (27b).

- vido de visiones una infinidat (28c).

- vido en poca hora una grant visión (29d).

- vido (a las tres guionas) (30a).

- con esta visión fue mucho embargada (34b).

- "Yo non sería digna de veer tan grant gloria" (38b).

- vido (la columna que llegaba al cielo) (41c).

- vido (Jacob y la scala caeli) (43b).

- vidieron (las vírgenes el árbol) (46c).

- vidieron en el cielo (finiestras foradadas) (49c).

- allá vidieron (las procesiones/jerarquías celestiales) (51d).

- aparesciólis luego (la jerarquía de calonjes) (55a).

- visto este convento (jerarquía de obispos) (66a).

- conosció la voz (de Urraca, su maestra) mas non podió veerla (78cd).

- non podié veerla, ca en cabo estaba (Urraca) (79b).

- falló muy rica siella (80b).

- vedié sobre la siella (81a).

- vido más adelante (el convento/jerarquía de ermitaños) (83a).

- y vido (a Galindo, un su paisano) (85a).

- y vido (a su padre, en el cielo) (85c).

- alçó Oria los ojos escontra aquilón, vido (la jerarquía de mártires) (86ab).

— vido (a los apóstoles) (89a).

- y los vido estar (a los evangelistas) (89c).

- "todo esto que vees a ti es otorgado" (habla Voxmea) (97c).

- fablólis Dios del Cielo, la voz bien la oyeron [...] pero non la vidieron [la su Majestat grande] $(103 \mathrm{~cd})$.

- oyó fablar a Christo [...] mas non podió veerlo a todo su taliento (no lo merecía) (105bc). 
- Dixol aún de cabo la voz del Criador (108a).

- en muy poquiello rato al cuerpo la tornaron (las tres guionas), espertó ella luego $(111 \mathrm{~cd})$.

- abrió ella los ojos, cató en derredor, non vido (a las guionas), vídose alongada (112abc).

- non cuidaba veer la hora nin el día que pudiesse tornar a essa confradía (113a).

- por estas visiones (no dio entrada a ninguna vanagloria) (114a).

- desque vido (las jerarquías) (117b).

- vido grant visión, tan grant como las otras (118ab).

- vínoli una gracia, mejor que nunca li vino (2 $2^{\mathrm{a}}$ visión) $119 \mathrm{c}$ ).

- vido venir (3 vírgenes, a media noche, después de haberse acostado muy cansada) (121a).

- ende a poco rato vino Sancta María (hay contacto físico -abrazo- entrambas) (129a).

- "Yo te daré un signo" (le dice la Gloriosa) $(137 \mathrm{~cd}$ ).

- "veráste en grant quexa" (la señal de la enfermedad) (139a).

- fue a Mont Oliveti en visión levada, vido ý tales cosas de que fue saborgada; sinon la despertassen (estando traspuesta) (142abcd).

- vido (el locus amoenus del Monte Oliveti) (143a).

- vido (la hueste de varones a recibirla) (144a).

- otras tales vidiera (compañas celestiales) en algunàs sazones $(145 \mathrm{c})$.

- vido (a Don Sancho) nunca lo ovo visto ( =conocido) (146ac).

- comenzó de traerla (Amuña su madre le forzaba a volver en sí), ovo a despertar $(147 \mathrm{~d})$.

- en aquella sazón non querrié espertar, ca sedié en grant gloria (visión del Monte Oliveti) e cuidava que nunca alla podrié tornar (148bd).

- aviélis poco grado a los despertadores (madre y sorores), ca sedié en grant gloria (149ac).

- disié entre los dientes con una voz cansada: "Monte Oliveti, Monte Olivetin (felicidad obsesiva) (150ab).

- "Oria abri los ojos, oirás buen mandado" (le dijeron su madre y las sorores) (153b).

- Luego que lo oyó este mandado (Oria) abrió los ojos, entró en su memoria e dixo: [...] "porque me despertaron so en grant querimonia" (154abcd).

- "si solo un poquiello me oviessen dexada (en la visión) grant amor me fizieran, sería terminada, ca entre tales omnes era yo arribada (155abc) (Se refiere a la Santa Compaña).

— "fui al Mont Oliveti en visión levada, vidi ý tales cosas" (157cd). 
- "vidi" (la segunda versión del locus amoenus) (158a y 159c).

- quanto fue acostada, fue luego adormida, una visión vido que fue luego complida (Amuña ve a su marido) (167abc).

- vido (a su marido con otros tres personajes/ánimas presagiando la muerte de Oria) (168ac y 169ad).

- despierta fue Amuña, la vision passada (127a).

- Non echó esti sueño la dueña (Amuña) en olbido (173a).

- conjuróla Amuña [...] "Fija si vision bidiestes o alguna historia, dezítmelo de mientre avedes la memoria" (175abcd).

- (Desde la muerte de Oria) andava la su madre por ella fetillada, solo que la pudiesse soñar una vegada, teniése por guarida $(188 \mathrm{~cd})$.

- ensoñó esta dueña (Amuña) un sueño deseado (190c).

- acostóse un poco [...] e luego soñó la su fija amada (191cd).

- estas palabras dichas (Oria) fuyóli a la madre de los ojos corales, despertó luego ella (203acd).

- vido sin estas obras (Amuña) muy grandes visiones (204a)

Podemos concluir que en el Poema de Santa Oria Berceo presenta un cielo escalonado en jerarquías sedentarias y procesionales. Las visiones de Oria alcanzan a ver seis escalas de virtudes humanas pero no las angélicas ni el trono supremo de la divinidad: el masculino trinitario y el femenino de la Gloriosa, teofanía que solo percibe la emparedada a través del oído. Esos estratos de santos parecen hacer tiempo en sus tribunas para el momento del Juicio Final, tema que en esta obra se omite.

Existe también un cielo anterior terrenal, paradisíaco, en el Monte Oliveti, lugar desde el que se accede al cielo superior.

En un espacio bien determinado hay una silla protagonista en espera de una cielo para Oria, personalizado y sedentario, además de coronas y palmas como galardón.

Queda de manifiesto una gloria de amor particular, sin tramoyas, donde Cristo y el alma se desposan y utilizan la silla como tálamo. Esta gloria no es para disfrute de los otros sentidos, ni de interés de clase, ni otros planes ajenos a la entrega en el amor y su conocimiento.

No se habla de la localización de la Gloriosa en ese cielo estratificado pero sí de su descensión para confortar la ausencia del cielo a la cilla de Oria.

La tierra y el cielo aparecen como dos ámbitos unidos por un espacio intermedio, la scala Dei y el paradisíaco locus amoenus. Como motor en esa ascensión, la paloma, símbolo de la gracia y de la presteza del alma que tiende hacia Dios, aunque no queda claro si el poder de la paloma/ 
alma es propio o prestado. Además, está el poder de los ángeles en estas asunciones de las tres vírgenes y Oria, que parece sube sola. ¿Se quiere contrastar, con la asunción de las guionas y la ascensión de Oria, el estado real que gozan las tres vírgenes (Celilia, Águeda, Eulalia) en el cielo, y el soñado $-\mathrm{y}$ por eso solipsista - de la emparedada, uno de cuyos fantasmas es el de poder volar?

Por contraste chocan el mundo imaginativo y maravilloso que presenta Berceo en las visiones de Oria y el mutismo ascético y seco a ras de tierra en la presentación de su muerte.

El cielo y el infierno configuran los modos de placer y de tormento a hechura de los de la tierra y es lógico, porque el cuerpo participa de ellos con el alma en la vita post mortem. La concepción del cielo, salvo en momentos de influencia aristotélica — de carácter intelectivo e inmaterial: el goce de la luz divina y el conocimiento exclusivo de Dios- es, predominantemente, sensorial y gozosa. En las visiones de Oria las relaciones terrenales (encuentro con familiares, conocidos y amigos) no son del todo reemplazadas por una fría comunidad celestial y una sociedad de ángeles, que aquí solo aparecen como ayudantes para subir a la gloria ${ }^{57}$.

57 El presente trabajo ha sido realizado dentro del Proyecto de Investigación PB971182: Análisis antropológico de las manifestaciones de culto a santos y vírgenes de Madrid. Quiero agradecer vivamente las lúcidas sugerencias y el contraste de opiniones para este artículo de mi amiga, la doctora Beceiro Pita. 
A través del Poema de Santa Oria, de Gonzalo de Berceo, se analiza el concepto de cielo, su estratificación y divisiones jerárquicas, atendiendo al grado de santidad de sus habitantes. Se estudia, además, la comunicación entre los mundos celestial y terrenal a través de los viajes al cielo y del cielo - asunciones y descensiones- que experimenta esta santa riojana que vivió emparedada entre 1043 y 1070 . Esta Vita, sacada a su vez de la escrita por el clérigo Muño, y que Berceo utiliza como fuente segura, muestra las distintas adherencias cultas y populares, acumuladas en estratos, de lo que se pensaba y creía del mundo celestial como premio. La importancia a la fidelidad en la transmisión - oral y escrita- de los textos hagiográficos que han de servir como exempla es otro de los temas, junto con el de la información directa del santo al biógrafo, en que, llamativamente, hace hincapié el escritor emilianense, que concluyó esta obra hacia el año 1252.

The author discusses Gonzalo de Berceo's Poema de Santa Oria, finished around 1252 , and analyzes its concept of heaven, with its stratification and hierarchical divisions according to the degree of sanctity of its inhabitants. He also examines the communication between the celestial and terrestrial worlds via the ascents to and descents from heaven that Santa Oria experiences, who otherwise lived locked up between walls from 1043 to 1070 . The Vita of this saint from the region of La Rioja, based on the work of the cleric Muño and used by Berceo as a reliable source, reveals a variegated number of elements, from high as well as popular poetry, that accumulated in layers and bear upon ideas and beliefs about the heavenly world. Other themes that Berceo emphasizes are the importance of trustworthiness in the transmission -both oral and written- of the hagiographic texts used as exempla and the direct information that the saint gave the biographer. 